University of Rhode Island

DigitalCommons@URI

Open Access Dissertations

1992

\title{
An Analysis of Altering the Value of a Classically Conditioned Predictive Cue
}

Paige A. Dibiasio

University of Rhode Island

Follow this and additional works at: https://digitalcommons.uri.edu/oa_diss

\section{Recommended Citation}

Dibiasio, Paige A., "An Analysis of Altering the Value of a Classically Conditioned Predictive Cue" (1992). Open Access Dissertations. Paper 913.

https://digitalcommons.uri.edu/oa_diss/913

This Dissertation is brought to you for free and open access by DigitalCommons@URI. It has been accepted for inclusion in Open Access Dissertations by an authorized administrator of DigitalCommons@URI. For more information, please contact digitalcommons-group@uri.edu. 


\title{
AN ANALYSIS OF ALTERING THE VALUE OF A CLASSICALLY CONDITIONED PREDICTIVE CUE
}

\author{
BY \\ PAIGE A. DIBIASIO
}

A DISSERTATION SUBMITTED IN PARTIAL FULFILLMENT OF THE REQUIREMENTSFOR THE DEGREE OF DOCTOR OF PHILOSOPHY INPSYCHOLOGY

UNIVERSITY OF RHODE ISLAND

1992

28628991 


\section{ABSTRACT}

Theoretically, predictive cues have a major role in conditioning. Both conditional stimuli and operant responses function in a way which provide information to a subject about what is to occur under a particular set of circumstances. Any available cue will have a particular relationship with any given outcome stimulus (SO) based on the probabilities of cooccurrences and non co-occurrences, whereby the resulting predictive value will impact on the behavioral consequences. A stimulus can produce behavioral effects it never caused prior to conditioning. Are those behavioral effects the result of the predictive value of the stimulus alone, or does the motivational value of the stimulus change? Could the resulting behavior be based on some combination of both? The value - both incentive value as well as predictive value of the predictive cue itself is of significance. Knowing about the manner in which cues are affected will have an effect on how they are used, how they will affect behavior and how they function in applied settings. Despite an abundance of valuable information pertaining to such events, several crucial issues remain to be examined. First, exactly how does the predictive value of the predictive cue influence behavior? Cues which are highly reliable should influence behavior in a very systematic manner. Depending upon the motivational value of the outcome predicted, a consistent approach or withdrawal behavior should be exhibited. Additionally, cues 
which are unreliable should have less systematic influence on behavior. Since such cues provide no reliable information regarding outcomes, no reliable behavioral consequences should be observed. The present research was designed to separate the predictive and incentive values of the predictive cue itself by examining the behavioral consequences of altering the incentive value of outcome stimuli on the incentive value of the cues that predict them. This design was employed to examine if the relative tendency of the animal to approach or withdraw from any particular predictor changed when the relative tendency to approach or withdraw from the outcome stimulus was altered. The questions specifically investigated were: in regard to a classically conditioned behavioral effect, to what extent does a stimulus retain or take on the initial value of the stimulus it predicts, and to what extent is it based upon the current (altered) value of the stimulus it predicts? The design employed provides a measure of the motivational value of predictive cues relative to the current motivational value of the outcome stimulus. In all circumstances it is the value of the outcome stimulus that was manipulated, while responding to or for the predictive cue $\left(\mathrm{S}_{2}\right)$ was measured. Thus, the behavioral consequences of the value of outcome stimuli on the value of the predictive cues was assessed. Subjects were 64 male Sprague-Dawley albino rats weighing 250 - $350 \mathrm{gm}$. All subjects were hungry and thirsty throughout the entire experiment. Subjects were randomly assigned to one of eight groups (eight subjects per 
group) and run through the sequence of the experiment as determined by the particular group. Group membership is indicated by a three unit code pertaining to the Sensory Preconditioning Configuration - Sensory Preconditioning Stimulus Presentation - Revaluation phase sequences. For example, subjects in group APL received Sensory Preconditioning Configuration A, Stimulus Presentation P, and Revaluation $L$. As a result of the above manipulations, the following should be true for both Sensory Preconditioning Configurations: 1) The $\mathrm{RN}$ group has no predictive value and provides information regarding the original, unaltered motivational value of $S_{1}$ and $S_{2} .2$ ) The RL group has no predictive value and provides information regarding the original, unaltered motivational value of $S_{2}$ and information regarding the devalued motivational value of $S_{1}$. 3) Group PN evidences the predictive value of $S_{2}$ and the inherent, unaltered motivational value of $\left.S_{1} .4\right)$ The $\mathrm{PL}$ group provides information regarding the motivational value of $S_{2}$ after $S_{1}$ has been devalued, as well as the devalued motivational value of $S_{1}$ and the predictive value of $S_{2}$. A $2 \times 2 \times 2$ Multivariate Analysis of Variance (MANOVA) with eight dependent measures ( $T_{1} \mathrm{P}, \mathrm{T}_{1} \mathrm{~S}_{2}, \mathrm{~T}_{2} \mathrm{~S}_{1}, \mathrm{~T}_{2} \mathrm{H}_{2} \mathrm{O}, \mathrm{T}_{3} \mathrm{~S}_{2}, \mathrm{~T}_{3} \mathrm{H}_{2} \mathrm{O}, \mathrm{T}_{4} \mathrm{~S}_{1}, \mathrm{~T}_{4} \mathrm{~S}_{2}$ ) was conducted. The MANOVA produced the following results: Configuration $(C), \quad F(8,47)=22.45, p<.001$; Stimulus Presentation (StP), $F(8,47)=0.61$, n.s.; Revaluation, (R) $F(8,47)=19.54, p<.001 ;$ Configuration $\times$ Stimulus Presentation, $F(8,47)=0.8$, n.s.; Configuration $\times$ Revaluation, 
$F(8,47)=10.36, p<.001$; Stimulus Presentation $\times$ Revaluation, $F(8,47)=0.93$, n.s.; Configuration $x$ Stimulus Presentation $x$ Revaluation, $F(8,47)=1.32$, n.s. Follow-up ANOVAs and Tukeys revealed an unexpected pattern of results. The data suggests that illness is what produced the quinine-water discrimination, but that prior to experiencing the salient contingent event of illness to quinine, water and quinine were not responded to differentially. Such a finding has strong implications for the Sensory Preconditioning phase. Since all animals had access to water in their home cages daily during all phases (except Revaluation and Testing), and were exposed to water in the training apparatus during Acclimation, animals (both Paired and Random) experienced presentations of saccharin and water in a random fashion. In essence, there was no contingent relationship in place for the Paired subjects and results indicate that all subjects responded as if no learning occurred during Sensory Preconditioning. Consequently, no predictive relationship was established so habituation to the taste of saccharin took place. Also, as a result of the absence of this predictive relationship, none of the differential experimental conditions were in place and subjects were unable to predict either the original or altered value of the CS. 
Acknowledgements

This all began longer ago than, I recently realized, l'd like to admit. I do not mean graduate school or this project in particular; I mean loving to learn and striving to be the best I could, regardless of what it was that I wanted to be. My parents, Terry and Joe DiBiasio, brought me up in an atmosphere of encouragement, security, and love. They taught me to be strong and honest, to learn and to love by example. Somewhere, a very long time ago, the seed for the completion of this project was planted.

More recently, they have helped, nurtured, and encouraged me; and they waited, ever so patiently. They have supported me emotionally and physically whenever necessary (only a year ago they were transporting me to and from school - and my mother actually helped handle rats and run research - when injuries from a car accident prevented me from doing so myself). Their strength , encouragement, and love has enabled me to persevere and achieve. This is symbolic of their achievement, as well as mine.

My sister, Paula, and brother, Alan, are extensions of my parents strength, encouragement and love. They have each provided me with emotional support, welcomed diversions, and mutual intellectual respect. They both have achieved in the academic arena (as well as in the "real world") and have listened, thoughtfully questioned and supported me every step of the way. Alan lent his pharmaceutical experience to this particular project early on, and Paula was in the trenches with me (as always - thank 
goodness!) when I needed help running animals. They are my family and my friends. They are respected, appreciated, and deeply loved.

My friends Tony Riccitelli and Sandy Smith have endured the loss of their friend from their lives over the past year and a half, and the entrance of a shadow, that occasionally showed up and expected everything to be the same. And it was! Tony has been supportive in every possible sense. He has always given me encouragement, praise, his keen critical analysis, and especially his loyal, enduring, and loving friendship. Sandy has perhaps felt my absence more than anyone yet she has remained my caring and loving friend. She has consistently kept me in touch with my emotional and spiritual side, regardless of how much I try to set it aside. I hope that I can be the friend to each of them that they are to me.

During the running of this project, I have been a fixture in the halls of Chafee. My fellow graduate students - my friends - Jim Arruda, Susan Curley, and Sherri Gold shared the same area of the building and became my direct and immediate support system. They understood! They were always there (as tends to be the habit with grad students) to offer me encouragement, listen to me complain (which I did - and still do - often), endure my days of bothersome chatter (that happens when you spend eight hours a day alone in the dark) and to remind me of the light up ahead.

Sue Curley is simply the most positive person I know. She always has a smile and kind word. Her warmth, genuineness, and clear thinking was (and remains) a bright spot in any day 1 
encounter her. In addition, Sue was kind enough to use her artistic abilities to draw a figure for this document for me.

Sherri is someone I have come to know and appreciate in a slow but secure fashion. Sherri is yet another friend who helped make those days of running research bearable; she spent many afternoons sitting with me in the dark. Her sincere, honest manner was a comfort.

Some of the most valuable and direct help I have received has been from Jim Arruda. Jim loaned me books and spent many hours with me sharing his knowledge and teaching me about using BMDP statistical computer package in order to conduct my analyses. He, too, listened, supported, asked many critical questions and encouraged me. Jim tolerated my stubbornness, endured the complexity of my experimental design, and after all remained my friend.

I hope all graduate students have the fortune I have been provided with by having such intelligent, caring and respected friends.

Without the help of Chris Stormer I would have certainly lost my mind!! The data collection part of this project actually involved running animals seven to ten hours a day, 18 out of every 22 day sequence. That meant working in a dark research suite supervising the apparatus and rotating animals through the prescribed conditions seven to ten hours a day. Chris was an undergraduate interested in getting some research experience. What a dose of experience landed on his resume! Chris started by helping with the set up of apparatus and being another pair of eyes, hands, and a 
questioner. He reliably showed up for several hours each week and helped with whatever frustrating task I was currently being faced with.

Once research actually started Chris took on the immense responsibility of handling the animals prior to the start of the experiment. This involved several long hours of sitting in the colony room gentling animals - a task that puts the reality of animal research in perspective. Again, Chris was patient and reliable. In addition, when the apparatus was cooperative, Chris would run animals and give me a break from the darkness to get some things done by light. When the apparatus warranted my presence, Chris often brought me lunch and sat in the dark with me and discussed the project, and life in general. Chris encountered each triumph, although they were few, and every frustration. He always showed up, he always helped, he always thought critically, and asked important questions. He listened to me (silent or talkative), he learned (a lot I hope!) and he NEVER complained. I cannot imagine having to conduct such a project without such valuable help. I am deeply indebted and appreciative of his help and friendship.

Drs Winifred Brownell, Charles Collyer, Lisa Harlow, Breck Peters, Dom Valentino, and Grant Willis are members of my dissertation committee. I have known each varying amounts of time and through a variety of situations. I am grateful to each for their respective contributions to this project. Their time, knowledge, and direction has been invaluable and immeasurable. 
Drs Charlie Collyer and Dom Valentino have been extremely dedicated to this project from the start. They have contributed much time and critical analysis to the project as well as being significant influences in my graduate education. I aspire to their standards of research and teaching.

I am certain that this project would have never been started, much less completed, if it were not for the support direction, encouragement and confidence of Dr. Albert Silverstein. Dr. Silverstein became my major professor at a very critical point in my education and has subsequently had a significant impact on me through the work we have done on this project. Dr. Silverstein has been a committed, loyal, supportive force. He has challenged me to think at a level I never knew existed. He has taught me with respect, kindness, endurance, and humor. Through each step of this project, no matter how frustrating or disappointing, Al looked beyond to focus me on success. I have learned many valuable things from Dr. Silverstein, about research, thinking and life. I have never encountered a teacher in my academic endeavors as positive, encouraging, and dedicated as Al Silverstein has been to me. He has challenged me to ever reaching intellectual heights. Al, thank you, for having the confidence in me that I needed to have in myself when this started, and for helping me to find it again in order to complete this project and move on.

To Dr. Silverstein, and each of you, my most sincere thanks. 


\section{List of Tables}

Table Number Title

1

2

3

4

5

6

7

8

9

10

11

12
Design

Means \& Sds for each group

MANOVA Source Table

Means and Sds of Suppression Ratio

$\left(\mathrm{S}_{1} /\left(\mathrm{S}_{1}+\mathrm{H}_{2} \mathrm{O}\right)\right)$ on Test Day 2

2×2 ANOVA Source Table for Test 2:

Suppression Ratio $\left(\mathrm{S}_{1} /\left(\mathrm{S}_{1}+\mathrm{H}_{2} \mathrm{O}\right)\right.$ )

$2 \times 2 \times 2$ ANOVA Source Table for Test 1:

Frequency of Lever Pressing for $S_{2}$

Means and Sds of Suppression Ratio

$\left(\mathrm{S}_{2} /\left(\mathrm{S}_{2}+\mathrm{H}_{2} \mathrm{O}\right)\right)$ on Test Day 3

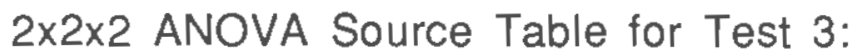

Suppression Ratio $\left(\mathrm{S}_{2} /\left(\mathrm{S}_{2}+\mathrm{H}_{2} \mathrm{O}\right)\right)$

$2 \times 2 \times 2 \times 2$ ANOVA Source Table for Test 3:

$\mathrm{S}_{2} \& \mathrm{H}_{2} \mathrm{O}$ Consumption

2×2 ANOVA Source Table for Saccharin/Quinine

Preference on Day 5 of Sensory Preconditioning

$2 \times 2 \times 5$ ANOVA Source Table Saccharin

Consumption per Day during Sensory

Preconditioning

$2 \times 2 \times 5$ ANOVA Source Table Quinine

Consumption per Day during Sensory

Preconditioning 
Figure Number Title

1

Drawing of Fluid Dispenser

2

CTA as indicated by Mean $\mathrm{S} 1 /(\mathrm{S} 1+\mathrm{H} 2 \mathrm{O})$

Consumption Test Day 2

3

Mean Lever Presses Test Day 1

4

Mean S2 Consumption Test Day 1

5

Mean saccharin consumption per day during

Sensory Preconditioning

6

Mean quinine consumption per day during

Sensory Preconditioning 
The circumstances which guide behavioral potential to action have provided experimental psychologists with unending avenues of exploration. To date "what is learned?" in conditioning remains fertile ground for investigation. Animals learn about the locations and availability of reinforcers and unconditional stimuli of primary motivational value, that is , of biological and/or emotional significance. In addition, through classical and operant conditioning, animals also learn about stimuli and events which predict future outcomes as a result of the contingent relationships of the stimuli and events involved. In classical conditioning the contingency establishes the predictive value of a conditioned stimulus (CS) for an unconditional stimulus (US). In the operant circumstance, the predictive value of a response (R) for a particular outcome $\left(S^{0}\right)$ is established. Therefore, stimuli (CSs) and events (Rs) acquire value for the animal that they did not have prior to conditioning. They acquire predictive value based on the motivational value of the outcome predicted, and allow an animal to prepare for the arrival of the outcome.

In considering the classical conditioning paradigm, a CS acquires predictive value if it produces a behavioral consequence it did not produce prior to conditioning (i.e., it evokes a conditioned response $[\mathrm{CR}]$ ), and if that value is different from its original value prior to conditioning (as measured by the relative tendency to approach or with draw from it). Predictive value leads to "functional equivalence" of the CS with the US (Rozeboom, 1958). That is, responding to the CS looks like responding to the US 
regardless of the motivational value (the desirability or undesirability) of the US. If predictive value is the totality "what is learned" then responding to the CS will always be based on the current motivational value of the US - even if that value somehow changes. But, is it only predictive value that is acquired through conditioning? Could the motivational value of the CS, itself, actually be altered through conditioning? Could "what is learned", be that the CS acquires or takes on as inherent, a new motivational value based on that of the US, in addition to (or even instead of) merely predictive value?

Rescorla, in the adaptation of his 1987 Eastern Psychological Association Presidential Address, in American Psychologist (Rescorla, 1988) started a new discussion of Pavlovian conditioning in terms of "...the learning of relations among events so as to allow the organism to represent its environment." (p.151). In essence, Rescorla was introducing a new type of cognitive view of conditioning based on "information" though, it is a view which has theoretical roots in the work of E.C. Tolman (e.g., Tolman, 1932). This new view of conditioning incorporates traditional empirical findings with some more recent results that Rescorla and his colleagues (Colwill \& Rescorla, 1985a, 1985b, 1986; Rescorla, 1980, 1985, 1987; Rescorla \& Cunningham, 1978) have produced. Rescorla's (1988) integration and reorganization of the empirical findings has had a major impact on the framework for the analysis of learning and pays special attention to the predictiveness of cues and events. Based on a variety of experiments designed to examine instrumental behavior through Pavlovian constructs, Rescorla 
(1987) also established a new foundation for the analysis of learning in general.

The key feature of this new cognitive view of conditioning is that "what is learned" from any particular event is information which allows an animal to interact with its environment in a successful manner because it can predict future events from present cues and events. The traditional view of conditioning argued that what an animal learned in a Pavlovian arrangement was that a neutral stimulus came to evoke a response that an inherently important unconditional stimulus (US) elicited. That neutral stimulus became a conditional stimulus (CS) which eventually, after repeated contiguous pairings with the US, simply could be substituted for the US. This substitution occurred because of the contiguity of the CS and the US. If they happened often enough, in close enough temporal proximity to each other, "stimulus equivalence" would occur (Pavlov, 1927).

Much research from Rescorla's lab indicates that simple contiguity and stimulus substitution theory are not substantiated in the data. They provide neither the necessary nor sufficient conditions for learning to occur. What the data suggest is that predictive contingency is sufficient and necessary for conditioning to take place.

A contingent relationship is one that provides information about the conditional probabilities of events in the animal's environment. It is reliable and predictive. It provides consistently predictable information to an animal regarding events that are coming that can be used to guide behavior. This will be based on 
the reliable cues and events of the current environment and the probabilities of future outcomes. Prediction enhances survivability; it is adaptive for the rabbit to smell the fox and take appropriate action (freeze or get out of reach) based on what the smell of a fox predicts (at the very least, a high speed chase).

Animals gain information in light of what the events in the environment tell them. Events that are contiguous in time do not necessarily provide predictive information. Redundant, unreliable, and unsystematic co-occurrences of stimuli or events can maintain contiguity but fail to affect contingency. Research clearly indicates that contingency, not contiguity, is the critical relationship. A basic premise that emerges from Rescorla's $(1987,1988)$ work is that in both operant and Pavlovian learning, the animal learns to predict the probable occurrence or non-occurrence of an outcome stimulus (SO), either an operant reinforcer/punisher or a Pavlovian unconditioned stimulus, which has a particular motivational valuation (usually a strong one). In the Pavlovian case it is a signal, the conditional stimulus, that provides the animal with the predictive cue. In the operant case it is the occurrence of the operant response class (R), that provides the subject with the predictive cue.

Theoretically, since the reliability of the relationship between a predictive cue and an outcome establishes predictive value, one of the factors that helps to guide behavior is the predictive value of the available cues. Any available cue will have a particular relationship with any given So based on the probabilities of co- 
occurrences and non co-occurrences whereby the resulting predictive value will impact on the behavioral consequences.

In addition, one might infer from the above stated premise that in both operant and Pavlovian conditioning the animal may also be learning to change the valuation of the predictive cues. That is, the cue may change from some relatively neutral initial value prior to conditioning to an incentive or aversive value based, in some way, on the outcome it now predicts. If presentation of the predictive cue has behavioral consequences that it did not have prior to conditioning (predicting a particular So with a particular motivational value) then perhaps the motivational value of the predictive cue has changed along with its predictive value. If so, it is possible that whenever the motivational value of an outcome stimulus is altered by any procedure, the motivational valuation of the predictive cue may also change. Such a change in valuation could be demonstrated by appropriate alterations in the animal's behavior. In the Pavlovian situation the appropriate alteration would be based upon a change in the probability of some approach or withdrawal response. In the operant situation the appropriate alteration would be indicated by a change in the probability of the operant response class itself.

Researchers have addressed "what is learned" in a multitude of ways over the years by probing to find general laws of learning. The new cognitive perspective is actually a reorganization of some not so new information, but it is different from the "old" cognitive views because it is more empirically grounded. Earlier cognitive views of conditioning (Harlow,1949; Kohler,1925; Tolman, 1948, 
1959) met with much criticism principally due to the lack of clearly specific empirical support rather than because they were inadequate theories. Work regarding "what is learned" which provides support for a cognitive perspective of learning can be found in some of the most innovative and valuable contributions to the body of literature regarding learning. Leon Kamin's $(1968,1969)$ research on "the blocking effect", and the Rescorla/Wagner model of conditioning (Rescorla \& Wagner, 1972; Wagner \& Rescorla, 1972) examine how the association of stimuli (CSs and USs) takes place (through autoshaping).

Both Rescorla and Wagner (Rescorla \& Wagner, 1972; Wagner \& Rescorla, 1972), and Kamin (1968,1969), set out to investigate a variation of the "US-reduction hypothesis" (Domjan \& Burkard, 1982, p. 95), an hypothesis that viewed Pavlovian conditioning as a US's ability to produce conditioning. Initially, a US has its full potential of conditionability, but as conditioning trials progress (the CS is paired with the US) it seem to have less additional conditionability potential. Kamin $(1968,1969)$ had examined circumstances where he predicted that learning would not take place based on the US-reduction hypothesis. He predicted that learning would not be as effective if a second stimulus was added to a Pavlovian conditioning arrangement in perfect positive correlation with a preexisting CS because such a stimulus would be introduced at a point when the USs conditionability strength would be greatly reduced. This came to be known as "the blocking effect". Further research on "the blocking effect" shed light on circumstances which enhanced conditioning as well as blocked it. Kamin $(1968,1969)$ 
found that blocking did not occur in situations when the second stimulus was not redundant and/or where it provided new or "surprising" information.

What Kamin's research $(1968,1969)$ and the Rescorla/Wagner model (Rescorla \& Wagner, 1972; Wagner \& Rescorla, 1972) indicate goes beyond mere conditionability of a particular response and the blocking effect. The notion of "surprisingness" has to do with contingency and predictability. Kamin's $(1968,1969)$ and Rescorla's and Wagner's (Rescorla \& Wagner, 1972; Wagner \& Rescorla, 1972) research, separately and in combination, provide empirical support for the concept of predictability as the key element of a cognitive view of conditioning, in response to the question "What is learned?". Kamin's research clearly demonstrates that redundant stimuli do not affect learning, but that "surprising" stimuli which add new information and enhance predictability, do influence learning. In addition, Rescorla and Wagner's mathematical model is consistent with Kamin's work and expands the notion of "surprisingness" (i.e., informativeness) to a number of other learning phenomena and paradigms, from blocking to conditioned taste aversions.

The Rescorla/Wagner model (Rescorla \& Wagner, 1972; Wagner \& Rescorla, 1972) is also rooted in the US-reduction hypothesis. It is a very precise mathematical model that accounts for conditioning and blocking as well as for a number of other conditioning phenomena. It predicts the associative strength of stimuli over conditioning trials with the US, based on the notion that there is an asymptotic level of conditionability that the US can 
support, and incorporates the "surprisingness" of that US (i.e., the discrepancy between the asymptotic strength of the US and the magnitude of the conditioned response (CR)). Specifically, the model gives most of the US associative strength to the CS early in the conditioning trials - when the US is most surprising and, hence, informative. Thus, such associative strength decreases over trials as the asymptotic level of surprisingness and conditionability decreases.

Egger and Miller (1962) conducted research examining informativeness and redundancy as it relates to contingency and contiguity. They manipulated the experimental conditions of their study such that the more contiguous cue was less informational and more redundant with a contingent cue. Their results indicated that contiguity was not sufficient for conditioning to occur and that informativeness (contingency) produced more effective learning. In addition, this research and subsequent work (Egger \& Miller, 1963), revealed that cues which were redundant yet informative also produced effective learning.

To more clearly examine this "informational" aspect of cues, Cohen, Calisto, and Lentz (1979) successfully attempted to separate the informational component of a contingency from the reinforcing component of it. Using chained schedules and secondary reinforcers, these researchers found that stimuli were only effective at maintaining behavior (and could serve as secondary reinforcers) when they were informational, otherwise they needed to be tied to primary reinforcers in order to maintain behavior over a long chain of reinforcement schedules. 
Rozeboom (1958) was one of the earliest and most insightful proponents of the need for a more empirical orientation to the possibility of the cognitive/informational perspective. In an analytically challenging article entitled, ' "What is learned?" - an empirical enigma', Rozeboom (1958) discussed the puzzling absence of empirical facts necessary to convincingly develop behavioral theories regarding "what is learned". These empirical facts, he asserted, lead to "empirical principles" which are the underlying general statements about the particular relationships of the variables at hand. He went on to identify what is missing in the way of empirical facts about the CS - US relationship in classical conditioning, and the nature of the CR. Rozeboom's question was in terms of what it is that the CS acquires from the reliable and predictive relationship it has with the US which causes a particular response class (CR) to emerge. There are two basic views that had been considered: 1) that a special connection, of some sort, is established between the CS and a response (commonly known as an $\mathrm{S}-\mathrm{R}$ association) such that the CS, after conditioning, brings about the CR. Thus, the CS is no longer affected by the current motivational value of the US, or 2) that a "functional equivalence" is established between the CS and the US, such that the CS operates as a signal for the US and is always influenced by the motivational value of the US.

The S-R perspective on "what is learned" need not consider the motivational value of the US in regard to the CS since it is the particular response being conditioned that is crucial. The US is of significance only in the respect that it produces the UR, which is 
what the CS gets associated with, and why the CR subsequently occurs. Once the S-R association is established, it is only affected by new $S-R$ associations. Changes in the $C R$ are produced by the $C S$ being associated with a new UR - as elicited by a US of a different motivational value. But the original $S-R$ association is not affected by the current valuation of the US. The CS simply "evokes" the particular $R$.

The S-R perspective differs significantly from a "functional equivalence" view. Proponents of a functional equivalence approach maintain that the CS comes to function in the same way that the US does. Functional equivalence means that a CS takes on the motivational value of the US and, for that reason, comes to "evoke" the same response as the US (Rozeboom,1958). Functional equivalence suggests that "what is learned" is an equivalent relationship between the CS and US, so that the valence of the CS is based on the current motivational value of the US. A more recent version of the functional equivalence hypothesis based on the work of Rescorla and his colleagues (Colwill \& Rescorla, 1985a,1985b, 1986;Rescorla, 1980,1982,1987,1988; Rescorla \& Cunningham, 1978), maintains that a "functional equivalence" between the CS and US is due to the contingent relationship between them which makes the CS a reliable and informative predictor of the US.

The specific example Rozeboom (1958) used to illustrate his point raises a question that remains unanswered, and is the issue which the present study was explicitly designed to investigate. That question is: with regard to a classically conditioned behavioral effect, to what extent does a CS acquire and retain the motivational 
value of the US at the time of conditioning, and to what extent is it's motivational value based upon the current motivational value of the stimulus it predicts, regardless of how it may since have been altered?

If a CS reflects the "current motivational value" of the US it predicts, the CS is "functionally equivalent" to the US and responding to the $\mathrm{CS}$ will be a preparation for and similar to that of the US. If a CS's value is based purely on it's ability to predict the US (i.e., it's predictive value), then the value of the CS will be based on the current motivational value or desirability of the particular US it predicts. If a CS acquires only predictive value during conditioning, then it will always be the functional equivalent of the US's current motivational value. On the other hand, if a CS acquires the initial motivational value of the US during conditioning, and it's value does not completely reflect the current motivational value of the US, what really occurs is that the inherent motivational value of the CS has been altered (instead of or in addition to the predictive value of the cue).

How, then, does a stimulus with no strong, pre-experimental valuation (i.e., it's inherent value is relatively neutral) acquire value and what is that value based on? A stimulus produces behavioral effects it never did prior to conditioning. Learning takes place. Are the behavioral effects the result of the predictive value of the stimulus alone, or does the inherent motivational value of the stimulus change? Could the resulting behavior be based on some combination of both? How does an odor, such as Chanel, come to be such a sensuous scent to someone?

A mere whiff may send an 
individual into a sensual tailspin if it has been predictive of a warm, valuable, intimate someone. Just a small sniff may make the adrenalin pump, the heart beat faster and the toes tingle. But, does it only do so because it predicts the occurrence of that valuable someone or does it actually acquire an incentive value of it's own? What happens if this predicted outcome, this warm, wonderful, valuable someone, is no longer warm, wonderful and valuable? Does that once sensational scent, if it now predicts a cold, and painful someone, still produce an amorous spin or will a lump appear in the throat and a knot in the stomach? That is, does the incentive value of the cologne (the predictive cue itself) change as the motivational value of the predicted stimulus changes? What was learned originally: Predictive value? Motivational value? Both?

If "what is learned" is purely predictive then the CS should only acquire predictive value. Predictive value would give the CS a value based entirely on the current motivational value of the US. That is, the acquired value of the CS would reflect the motivational value of the US regardless of what that value is. If the motivational value of the US was somehow enhanced, then the value of the CS would also increase; if the motivational value of the US decreased (i.e., the US was devalued), then the value of the CS would also decrease. At the opposite end of this continuum, if "what is learned" is purely acquired motivational value, then the value of the CS should change from its original value to a new value only when it is being conditioned to the specific motivational value of the US, and it would retain that particular motivational value until it is 
extinguished to the US or reconditioned to a new US, regardless of any subsequent alterations in the motivational value of the US.

The predictive value of a CS may be conceptually separate from acquired motivational value (incentive or aversive) but the existing research has not provided the controls necessary to discern the behavioral consequences of these factors separately. Information regarding the valuation of predictive cues helps account for some complex behaviors which appear to be maintained not by the primary outcomes encountered but by those secondary stimuli which predict them. Such information may help teachers in selecting stimuli and responses to facilitate teaching, and classroom management, therapists in treating patients with maladaptive behaviors such as phobias, mental health workers in helping their clients to maintain appropriate, adaptive behaviors, and a variety of others in a multitude of settings. Such issues pose a second important question regarding the value of a predictive cue, which has to do with its original motivational value. That is, can the motivational value of the cue itself be significantly altered from its original motivational value by the motivational value of the outcome which it predicts?

Recent research, although it has often presented related information, has not yet precisely addressed the above questions because of limitations of the kinds of experimental designs employed. The designs used in such investigations have provided appropriate controls for assessing alterations in the motivational value of outcome stimuli but have rarely provided the controls to 
clearly assess the motivational value of the predictive cues themselves or what these values are based on.

The present study was designed to separate the motivational and predictive values of a predictive cue by examining the behavioral consequences for that cue of altering the motivational value of an outcome stimulus without the presentation of the cue. This design was employed to examine if the relative tendency of the animal to approach or withdraw from any particular predictor changed when the relative tendency to approach or withdraw from the outcome stimulus was altered, in isolation from the cue that predicts it.

Rescorla and Cunningham (1978) employed a sensory preconditioning design, with compound liquid taste stimuli, to evaluate changes in responding to a preconditioned stimulus $\mathrm{S}_{2}$ (the CS) due to the altered motivational value of the US $\left(S_{1}\right)$. If the value of $\mathrm{S}_{1}$ had changed, they reasoned that a new response to $\mathrm{S}_{2}$ should occur. Results indicated that when $\mathrm{S}_{1}$ had been devalued (by making subjects ill after they taste it), a decrease in responding (consumption) to $\mathrm{S}_{2}$ (the CS) occurred.

Colwill and Rescorla (1985) addressed the issue in the operant paradigm by examining operant responding in a two response (lever pressing and chain pulling), two reinforcer (sucrose pellets and food pellets) choice situation, after the primary reinforcer $\left(S^{\circ} 1\right)$ to one of the responses $\left(R_{1}\right)$ had been devalued through making subjects ill. If the value of one of the $S^{\circ} s$ had been changed, the response rate for that particular response should demonstrate this change. Results of this study indicated that 
altering the value of the reinforcer had an impact on responding; there was a decrease in the probability of the response which was predictive of the devalued reinforcer.

Thus, in both the operant and the Pavlovian paradigms an alteration in the animals' behavior was demonstrated after devaluation of a predicted outcome. However, these alterations need not necessarily be accounted for by the changes in the motivational value of the predictive cue itself, since the appropriate controls were not employed to isolate such effects from the predictive value of the cues by the experimental designs used in these studies. Rescorla and Cunningham (1978) never completely separated predictive from motivational value. In all of their groups, compound stimuli were used during the sensory preconditioning phase to establish a predictive relationship. Subsequently, Rescorla and Cunningham devalued one of the components of the compound (thereby altering it's motivational value), but predictive value was maintained as well. There were no groups that controlled for stimulus exposure but did not have the predictive relationship in place. A predictive contingency was in all place for all groups. Rescorla and Cunningham would have had to break up the compound stimulus (which would disrupt the predictability of the relationship) in order to manipulate motivational value without confounding it with predictive value.

Colwill and Rescorla (1985) did not adequately separate predictive from motivational value either. They employed an operant paradigm in which a particular response predicted a particular outcome. For all groups, the response - outcome 
contingeny was always maintained, which results in confounding predictive and motivational value. In addition, they did not provide the conditions needed to examine the original value of the predictive cue. A control condition in which no devaluation took place for either outcome would have been necessary to draw assess motivational value from the original value of the stimulus. As a result, the original motivational value of the predictive cue could not be separated from its acquired motivational value. These studies were designed to examine S-S and R-S associations. As designed, they provide information regarding such associations and information about predictiveness of cues and outcomes. The strategies used to illuminate these points also shed light on the consequences of altering the value of an outcome. As the above results indicate, altering the value of an outcome does have an influence on the predictive cues but the nature of that influence cannot be specified conclusively from the data. In both studies (Colwill \& Rescorla,1985; Rescorla \& Cunningham,1978), a variety of additional controls would have been needed to investigate predictive and motivational value. Rescorla and Cunningham's (1978) research demonstrates that $S_{2}$ predicts $S_{1}$ and implies that $S_{2}$ has a particular motivational value. What that value is and what it is based upon has not been examined.

Neither Rescorla \& Cunningham (1978), nor Colwill and Rescorla (1985), altered the setting from training to testing sessions, and neither used $S_{2}$ as an outcome to either a new operant or a different predictive cue. Thus it is possible that responding to $\mathrm{S}_{2}$ changed only because that cue predicted a less valuable outcome 
and that the motivational value of $S_{2}$ remained unaltered to some extent. One strategy which would add control for assessing the value of the predictive cue itself would be to alter the setting and the response from training to testing sessions and use the predictive cue $\left(\mathrm{S}_{2}\right)$, which was established during conditioning, as an outcome stimulus for a different response in testing. Such a procedure would eliminate stimulus generalization as well as cue predictiveness as explanations for changes in responding. Stimulus generalization could account for an animal giving the same response to a new stimulus in the same setting and cue predictiveness would also be maintained in the same setting. Also, it would use $\mathrm{S}_{2}$ in a manner which would demonstrate the motivational value of the predictive cue itself, rather than reflect only the value of the outcome stimulus.

Another factor requiring control when studying changes in the valuation of predictive cues is the possible role of response energization in affecting behavior change during testing. Proponents of response energization suggest that changes in responding during the test phase are due to the occurrence of any outcome stimulus presented at that time rather than due to the actual valuation of the stimulus. The animal is ready to respond and the contingent presentation of any stimulus during testing facilitates or energizes responding. That is, in any operant situation, the introduction of an outcome stimulus, presented contingently upon the occurrence of a previously reinforced response, facilitates the likelihood of that response being emitted. Any outcome stimulus could "energize" the response just because it is being 
presented. For example, if a rat has been reinforced with food pellets for lever pressing during training, responding should persist longer if a light is presented contingently than if no outcome stimulus is available. One strategy to control for such an explanation of response change would be to employ control groups which receives the CS noncontingently during testing, along with groups which receive the CS contingently as the So. Responding due to energization would produce changes in both the contingent and the noncontingent delivery groups equally, since the outcome would energize the response in the groups, rather than its predictability.

The present research examined the behavioral consequences for the predictive cues whose predicted outcome had been motivationally altered. A variety of procedures were employed which provided the controls necessary to address some of the above stated issues and eliminate alternate explanations for the results to be obtained. This study was conducted employing a combination of three research paradigms, sensory preconditioning, taste aversion learning, and operant analysis of behavioral consequences. Animal subjects (rats) were used. A brief review of these procedures and the relevant literature will illuminate the critical components of these paradigms.

The classical conditioning paradigm of sensory preconditioning involves an initial phase of presenting two (relatively neutral) stimuli $\left(S_{2}\right.$ and $\left.S_{1}\right)$ in a reliable and predictive manner (i.e., $S_{2}-S_{1}$ ) (Brogden,1939; Rescorla,1980). Subsequent to this pairing, $S_{1}$ is used in a typical Pavlovian arrangement such that $S_{1}$ becomes a CS predictive of a US with a particular motivational value $\left(\mathrm{S}_{1}-\mathrm{US}\right)$ and 
eventually produces the $C R$. The $S_{2}$ and $S_{1}$ relationship is then examined in a third phase by evaluating the behavioral consequences of $S_{2}\left(S_{2}-\right.$ ?). If $S_{2}$ produces the $C R$, then $S_{2}$ and $S_{1}$ have been preconditioned and a predictive relationship has been established. That is, learning took place between two relatively neutral stimuli with no overt behavioral consequences observed.

Taste aversion learning is a phenomenon that demonstrates a "prepared" response (Seligman, 1970) in classical conditioning. Prepared responses are responses that are learned more quickly, with fewer errors, and extinguish more slowly than other learned responses. A conditioned taste aversion (CTA) is an avoidance response to a particular taste/flavor that has been associated with gastric illness (Garcia, Kimeldorf, \& Koelling, 1955). Taste aversions are learned quickly - very often in one trial - can be learned with unusually long durations between the taste and illness interval (interstimulus interval), are affected by familiarity of the stimuli, and especially the interoceptive/exteroceptive nature of the stimuli (Bond \& DiGuisto,1976; Garcia \& Koelling, 1966; Kalat, 1974; Revusky \& Garcia, 1970).

An operant analysis of behavioral effects involves examining performance under a variety of experimental and control conditions in light of the outcomes they produce. Investigating the relative tendency of an animal to emit a particular response class under a specific set of circumstance provides information regarding the behavioral control values of the outcomes that are contingent on the various response classes. Employing the principles of operant 
conditioning allows for the assessment of the control components of previous learning paradigms.

A variety of experimental techniques were incorporated into this research in order to effectively examine the value of the predictive cues used. Three major manipulations - each with two levels - were used in various phases of this experiment for a total of eight conditions to complete the experimental design. A separate independent group of subjects was used for each condition. In an attempt to assess the motivational value of predictive cues after altering the motivational value (devaluing) of the outcome stimuli they predict, a classical conditioning procedure was employed. During the Revaluation phase subjects were exposed to conditions which was designed either to devalue the outcome stimulus or maintain its prior value. Devaluation was accomplished through the use of an intraperitoneal (i.p.) injection of lithium chloride ( $\mathrm{LiCl}$ ). Such an injection creates gastrointestinal distress, a typical procedure in CTA. Maintenance of the initial value was established through the use of an i.p. injection of sodium chloride $(\mathrm{NaCl})$. This is an injection of saline and should have no significant effects on the subject. The Revaluation phase was intended to assess the effect of altering the value of the outcome stimulus in the experimental conditions.

Two of the the major manipulations in the present research occurred during the Sensory Preconditioning phase. This phase is of paramount importance because an investigation of the relationship between a predictor stimulus and an outcome stilulus which was established prior to any revaluation of the outcome is necessary to 
accurately assess the influence of both the initial motivational value of the predictive cue and its value after the outcome which it predicts has been altered. The manipulation of Stimulus Presentation involved a basic control for demonstrating the effects of a reliable, predictive relationship between these two sti,uli (CS and US). During the Sensory Preconditioning phase subjects were exposed to either Paired (P) or Random (R) presentations of the stimuli $S_{1}$ and $S_{2}$, allowing a comparison the establishment of a contingent relationship versus a random relationship between these stimuli.

In addition, there was a manipulation of Stimulus Configuration during the Sensory Preconditioning phase. In the present study, $S_{2}$ and $S_{1}$ were both gustatory stimuli: a saccharin solution and a quinine solution. $\mathrm{S}_{2}$ and $\mathrm{S}_{1}$ solution configurations were manipulated as an independent variable; that is, half of the groups received saccharin as $S_{1}$ and quinine as $S_{2}$ (Configuration $A$ ) while the remainder received quinine as $S_{1}$ and as saccharin $S_{2}$ (Configuration B). This was incorporated into the design in order to allow generalization of the stimuli to be examined. This manipulation of Stimulus Configuration examines the possibility that the initial motivational values of CSs and USs may affect learning. Also, it provides information regarding the precise $S_{2}$ and $S_{1}$ value configuration since saccharin and quinine are not equally desirable pre-experimentally. That is, with initial value configurations of "greater to lesser" and "lesser to greater".

The Test phases were used to examine whether the value of the predictive cue had changed. Testing probed whether the post- 
Revaluation value of the predictive cue was based on 1) the initial value of the outcome stimulus (i.e., it was purely predictive value that was learned), 2) the current (revalued) value of the outcome stimulus (i.e., it was purely motivational value that was learned) or 3) some combination of predictive and motivational value. In addition, assessment of original motivational value of the CSs and USs employed could be established as well as any alteration in these values after Sensory Preconditioning without devaluation of $S_{1}$.

The most crucial test, of the several employed, assessed the motivational value of the predictive cue by presenting it contingently as outcome for a response class whose topography was different from anything subjects did during the conditioning phase. In such a test, the predictive cue is presented to the animal if, and only if, it performs the operant. Such a pattern of presentation of stimuli parallels a conditioned reinforcement or conditioned punishment paradigm. In the conditioned punishment paradigm, the predictive cue, which predicts a newly devalued outcome, is presented contingent upon the response, while in the conditioned reinforcement paradigm, the predictive cue, which predicts a newly positively valued outcome, is presented contingent upon the operant. If the animal does not perform the operant it receives no presentations of the stimulus. Responding in this situation is reflective of the current motivational value of the predictive cue. Thus for predictive cues with $\mathrm{S}^{\circ} \mathrm{s}$ which have been devalued, a decrease in responding and/or a more rapid extinction should be observed than with control groups; whereas such a decrease should not be observed to cues which have not been devalued. 
An overall schematic representation of the experimental design and the differential treatments in each group can be found in Table 1. Such a design facilitates a more direct examination of the predictive cues and presents more parsimonious information as well as eliminates alternate explanations for the results.

\section{INSERT TABLE 1 ABOUT HERE}

It was hypothesized that previously established contingencies between relatively neutral stimuli could affect subsequent behavioral consequences of those stimuli and that those behavioral consequences would be influenced by both the predictive value of the contingency as well as the current motivational values of the stimuli involved. Specifically, it was predicted that the Paired and poisoned (PL) groups would demonstrate the behavioral effects of both the predictive and motivational values of the stimuli (the CS and US), while the Random unpoisoned (RN) groups would provide information regarding only the original motivational values of $S_{2}$ and $S_{1}$ (since the was no predictive relationship between the stimuli and no illness).

The Revaluation phase provided the basis for comparing the altered versus maintained motivational value of the US before and after its value was altered. $\mathrm{LiCl}$ groups had the motivational value of the US devalued (altered), while $\mathrm{NaCl}$ groups maintained the initial value of the US. Therefore, Paired (PL) LiCl groups had a predictive $\mathrm{CS}$ and a devalued US, Paired $\mathrm{NaCl}$ ( $\mathrm{PN}$ ) groups had predictive CS and the initial motivational value of the US, Random 
LiCl (RL) groups had a non-predictive CS and a US with an altered motivational value and $\mathrm{Random} \mathrm{NaCl}(\mathrm{RN})$ groups had neither any predictive value for the CS nor any altered motivational values for the US. This group therefore provided information regarding only the initial motivational values of the CSs and USs.

The Configuration manipulation transposed the use of quinine and saccharin as CS and US. Such a manipulation controlled for any difference in the initial values of these two stimuli and the possibility that those initial values could have an influence on either the predictive or motivational values of the stimuli involved within the same conceptual framework as stated above.

As a result of the above manipulations, the following should be true for both Configurations $\mathrm{A}$ and $\mathrm{B}$ :

1) The RN group has no predictive value for $S_{2}$ and provides information regarding the original, unaltered motivational value of $S_{1}$ and $S_{2}$.

2) The RL group has no predictive value for $S_{2}$ and provides information regarding the inherent, unaltered motivational value of $S_{2}$ and information regarding the devalued motivational value of $S_{1}$.

3) Group PN reveals the predictive value of $S_{2}$ and the inherent, unaltered motivational value of $S_{1}$.

4) The PL group provides information regarding the motivational value of $S_{2}$ after $S_{1}$ has been devalued, as well as the devalued motivational value of $S_{1}$ and the predictive value of $S_{2}$. 
In order to assess the original values of the CS and US, the predictive value of the CS, the motivational value of the CS, as well as the initial, and current (altered) values of the US, a variety of dependent measures were employed. Test 1 used the contingent delivery of $S_{2}$ for a lever press operant in order to directly assess it's motivational and predictive value. Test 2 examined the motivational value of the US (initial or altered) as compared to water by measuring $S_{1}$ and water consumption while Test 3 investigated the predictive (or non-predictive) and/or motivational value of the CS as compared to water by measuring $S_{2}$ and water consumption. Test 4 compared the values of the CS to that of the US directly by measuring the amounts of $S_{1}$ and $S_{2}$ consumed. Only Test 1, however, fulfills all the requirements necessary to qualitatively assess the relative influence of original and altered motivational value of $S_{1}$ upon the motivational value of $S_{2}$, as discussed above.

If "what is learned" is purely predictive value, then in groups where a predictive relationship exists ( $\mathrm{P}$ groups), it is expected that the value of the CS would reflect the current value of the US, regardless of whether it is altered or not. Whereas, if "what is learned" is purely motivational value, then the CS should reflect the initial value of the US during the initial conditioning circumstances regardless of the current value of the US. The CS would take on new inherent value as compared to it's original value as reflected by non-predictive (Random) groups. If both predictive and motivational information is "what is learned", then predictive and motivational values should be different from the original values 
revealed in the RN groups. Responding to the CS in PL, PN, and RL conditions should demonstrate intermediate value based on some combination of both the initial and the current motivational value of the US.

\section{Method}

Subjects

Subjects were 64 male Sprague-Dawley albino rats weighing 250 - $350 \mathrm{gm}$. All subjects were hungry and thirsty throughout the entire experiment. They were maintained at approximately $80 \%$ of their free feeding weight and were given access to water for 20 min a day in their home cages housed in the animal colony room. Subjects were randomly assigned to one of the eight experimental groups (eight subjects per group) and run through the sequence of the experiment as determined by the particular group's assigned condition.

Group membership is indicated by a three unit code pertaining to the Sensory Preconditioning Configuration - Sensory Preconditioning Stimulus Presentation - Revaluation phase sequences. For example, subjects in group APL received Sensory Preconditioning Configuration A, Stimulus Presentation $\mathbf{P}$, and Revaluation L. Each phase is described in detail below. Apparatus

Two identical Coulbourn Instrument, Inc., Modular Small Animal Test Cages, model number E10 - 10, were employed. Each operant chamber measured $30 \times 24 \times 30 \mathrm{~cm}$. During Acclimation, Lever Press Training, Sensory Preconditioning, and Revaluation (the acquisition phases), each operant chamber was housed in a $62.5 \mathrm{x}$ 
$62.5 \times 70.5 \mathrm{~cm}$ sound attenuated chamber. Each sound attenuated chamber was equipped with a 15 watt house light and a ventilation fan which also provided white noise.

During all Test phases the same operant chambers were housed in sound attenuated chambers in a different experimental suite. The orientation of the operant chambers in the boxes was changed from that of the acquisition phases. Boxes were rotated 180 degrees such that they now opened facing east and all feeding, watering and lever pressing equipment was on the north wall of the operant chamber, as opposed to the chamber facing west with all equipment located on the south wall of the chamber during the acquisition phases. In addition, each sound attenuated chamber was equipped with a 6 watt house light and a ventilation fan.

As the equipment requirements of the operant chamber changed from phase to phase, the equipment was removed from and/or added to the chamber's equipment wall. The wall to the right of the front opening of the chamber was a three column panel wall in which a variety of equipment panels could be used. All equipment specific to each phase was located on this wall. During all phases standard electromechanical equipment was employed to operate the necessary apparatus. The following is a list of the standard equipment used, as needed for each phase.

Lever panel - a $7.75 \times 4 \mathrm{~cm}$ panel with a standard lever centered 2.5 $\mathrm{cm}$ from the chamber floor on it (Coulbourn Instrument, Inc., Model \#E22-01).

Food cup panel - a Coulbourn Instrument, Inc., Liquid Dipper/Pellet Cup, model number E14 - 06, 
Pellet dispenser - A Gerbrands Corp., pellet dispenser, model number $G 5120$, was used. It delivered Bio-Serv $45 \mathrm{mg}$ Dustless Precision Pellets, number F 0021.

Fluid spout panel - a metal panel fitted for the panel wall of the operant chamber with a custom $1.5 \times 2 \mathrm{~cm}$ oval shaped cut out $3 \mathrm{~cm}$ from the grid floor and centered horizontally on the panel was used to allow the fluid spout to be introduced into the chamber.

Fluid dispenser - a custom designed motor operated, rotating and retractable fluid dispenser was used. Polypro Barrel Reservoirs (EFD $30 \mathrm{cc}$ ) and caps were mounted on standard drink tubes through the rotating disk which could be introduced and retracted from the chamber by extending $2 \mathrm{~cm}$ from the base (see schematic in Figure 1). This dispenser was located outside the operant chamber behind the fluid spout panel to allow the tubes to be introduced into the chamber.

\section{Insert Figure 1 About Here}

The three fluid tastes dispensed were tap water, a .00006-M quinine monohydrochloride solution (Rescorla \& Cunningham, 1978), and a $.15 \% \mathrm{w} / \mathrm{v}$ sodium saccharin solution (Braveman \& Jarvis, 1978). Both the quinine and saccharin solutions were made with bottled Natural Spring water.

All injections were ip injections using a $25 \times 5 / 8$ gage needle and a $1.0 \mathrm{cc}$ siringe. Injections were either a $.9 \% \mathrm{w} / \mathrm{v}$ sodium 
chloride $(\mathrm{NaCl})$ solution (saline)(Braveman \& Jarvis, 1978) or a 3.0 $M$ lithium chloride (LiCl) (Rescorla \& Cunningham, 1978) solution.

\section{Procedure}

Eight groups were included in this experiment. All groups were run through a sequence of experimental phases with differing treatment at the appropriate phase for each particular group. The sequence was as follows: Acclimation, Lever Press Training, Sensory Preconditioning, Revaluation, Lever Press Retraining, Test 1, Test 2, Test 3 , and Test 4 . In terms of the above experimental phases and the necessary control groups, the eight groups included were: APL, APN, ARL, ARN, BPL,BPN, BRL, BRN. This coding reflects only the Sensory Preconditioning Configuration - Sensory Preconditioning Stimulus Presentation - Revaluation phase sequence, since all subjects are exposed to the same conditions in all other phases.

During all phases of the experiment, any time an animal was in the operant chamber being run though a particular sequence, the house light and fan in the apparatus were on.

Acclimation. All groups were exposed to this phase in exactly the same manner. It consisted of two components which were both conducted on day 1 . First, each animal was placed in the apparatus for $10 \mathrm{~min}$ with water available through the drinking spout. The spout was introduced and retracted from the operant chamber on a $30 \mathrm{~s}$ schedule (i.e., $30 \mathrm{~s}$ in and available, $30 \mathrm{~s}$ out and unavailable).

Approximately two hours later each subject was replaced in the operant chamber for another $10 \mathrm{~min}$, with the lever and food 
cup available (the drinking apparatus had been removed), and with five pellets of food in the cup. During this component of Acclimation the lever was in operation and provided pellets on an FR 1 schedule if the animal pressed the lever.

Lever Press Training. Lever Press Training began on day 2 of the experiment. The lever panel, food cup panel, and the food dispenser were in operation during this phase. All subjects were magazine trained, shaped, and lever press trained to food pellets in five sessions, one per day. Session 1 ranged from one half to one hour; the remaining four sessions were one half hour long. All subjects had to meet a criterion of 100 presses on a VR 10 schedule during session 5 . Subjects that did not meet the criterion were excluded from the experiment. The number of responses made and reinforcers delivered during each session were recorded.

Sensory Preconditioning. Two days following the completion of Lever Press Training the Sensory Preconditioning phase began. Both the fluid spout panel and the fluid dispenser were in use during this phase. Half of the subjects received Sensory Preconditioning Configuration $A$, in which $S_{1}$ and $S_{2}$ were saccharin and quinine, respectively, while the other half of the subjects received Sensory Preconditioning Configuration $B$ in which $S_{1}$ and $S_{2}$ were quinine and saccharin, respectively. Subjects in these groups (Configuration $A$ and $B$ ) differed only in the solution assignment $\left(S_{1}\right.$ or $\left.S_{2}\right)$. All other manipulations during this phase occurred in the same fashion to both subjects experiencing Configuration $\mathrm{A}$ and Configuration $\mathrm{B}$. 
During this phase, all subjects received five sessions (one session per day for five consecutive days) with 20 presentations of $S_{2}$ and 20 presentations of $S_{1}$ in each session. Half of the subjects in each configuration group were exposed to 20 paired $(P)$ presentations of $S_{2}$ and $S_{1}\left(S_{2}-S_{1}\right)$, while the remainder were exposed to 20 truly random presentations of $S_{2}$ and 20 truly random presentations $S_{1}\left(S_{2} / S_{1}\right)$. Exposure indicates that the animals were in the operant chamber while stimuli were presented. Presentations consisted of the appropriate taste fluid spout being introduced into the apparatus and being available for consumption.

For subjects in the $\mathrm{P}$ groups, a $10 \mathrm{~s}$ presentation of $\mathrm{S}_{2}$ was followed by a $10 \mathrm{~s}$ presentation of $S_{1}$ with a $20 \mathrm{~s}$ interstimulus interval (ISI) and a $50 \mathrm{~s}$ intertrial interval (ITI) for an overall trial interval of $90 \mathrm{~s}$. Subjects in the R groups were exposed to $10 \mathrm{~s}$ presentations of $S_{2}$ and $10 \mathrm{~s}$ presentations of $S_{1}$ in a truly random fashion, with ISI and ITI ranges of $20-50 \mathrm{~s}$, such that the overall trial interval was also maintained at $90 \mathrm{~s}$. The amounts of $S_{1}$ and $S_{2}$ consumed by each subject during each session was recorded. Revaluation. Two days after the completion of the Sensory Preconditioning phase, Revaluation began. Revaluation consisted of one 20 min session per day for three consecutive days. All subjects were given $20 \mathrm{~min}$ free access to their respective $S_{1}$ solution in the operant chamber with the fluid dispenser and spout panel operating. Animals were not given water in their home cages. Access to the $S_{1}$ solution was the only drinking opportunity they received during this phase. When removed from the operant chamber each subject was administered an ip injection of either 
LiCL or $\mathrm{NaCl}$ at a dose of $1 \mathrm{ml} / \mathrm{kg}$ bodyweight. Half of the subjects in each of the $P$ and $R$ groups received $L i C l$ (APL,ARL,BPL,BRL) and the remaining half of each group received $\mathrm{NaCl}$ injections (APN,ARN,BPN,BRN).

Lever Press Retraining. This was one $20 \mathrm{~min}$ session the day after the completion of Revaluation to reestablish the lever press response. The experimental circumstances were identical to the initial Lever Press Training phase - the lever panel, food cup panel, and the food dispenser were in operation. Pellets were delivered on a VR 10 schedule. The number of responses made and reinforcers delivered was recorded for each subject.

Test 1 ( $T_{1}$. Test 1 (as well as the remaining test phases) took place in a different experimental suite from the acquisition phases as noted above. Test 1 occurred the day after Lever Press Retraining. All subjects were placed in the operant chamber with the lever panel, fluid spout panel, and the fluid dispenser in operation for a 20 min session. S2 was delivered on a VR 10 schedule for lever pressing. The number of responses (presses) made $\left(T_{1} P\right)$, and the amount of $S_{2}\left(T_{1} S_{2}\right)$ consumed was recorded for each subject.

Test $2\left(T_{2}\right)$. Test 2 followed Test 1 by one day. Test 2 was a two bottle choice test. Animals were given $20 \mathrm{~min}$ free access to $\mathrm{S}_{2}$ and tap water simultaneously, with the fluid spout panel and the fluid dispenser equipment available. The right/left position of the different taste solutions were counterbalanced within subjects and groups, such that the positions alternated from right to left across 
Test days. The amount of each fluid consumed was recorded for each subject $\left(T_{2} S_{1} \& T_{2} H O\right)$.

Test 3 ( $T_{3}$ ). Test 3 was another two bottle choice test. It occurred 24 hrs after Test 2 under the same apparatus circumstances. Animals were given $20 \mathrm{~min}$ free access to both $\mathrm{S}_{1}$ and tap water, simultaneously. Again, the amount of each fluid consumed was recorded for each subject $\left(\mathrm{T}_{3} \mathrm{~S}_{2} \& \mathrm{~T}_{3} \mathrm{H}_{2} \mathrm{O}\right)$.

Test 4 (T4). One day after Test 3 , Test 4 was conducted. Under the same apparatus circumstances as the previous two tests, Test 4 offered a two bottle choice test of $S_{1}$ and $S_{2}$, with 20 min free access to both fluids. Consumption was recorded $\left(T_{4} S_{1} \&\right.$ $\left.\mathrm{T}_{4} \mathrm{~S}_{2}\right)$.

\section{Results}

Means and standard deviations were computed for each group on all dependent measures and are presented in Table 2. Although consumption levels were quite low for some measures standard deviations indicate that the scale was sensitive enough to detect still lower consumption, thereby avoiding floor effects.

A $2 \times 2 \times 2$ Multivariate Analysis of Variance (MANOVA) with eight dependent measures ( $T_{1} P, T_{1} S_{2}, T_{2} S_{1}, T_{2} H_{2} \mathrm{O}, T_{3} S_{2}, T_{3} H_{2} \mathrm{O}$, $T_{4} S_{1}, T_{4} S_{2}$ ) was conducted. The MANOVA produced the following results: Configuration $(C), F(8,47)=22.45, p<.001$; Stimulus Presentation (StP), $F(8,47)=0.61$, n.s.; Revaluation, (R) $F(8,47)=$ 19.54, $0<.001$; Configuration $\times$ Stimulus Presentation, $F(8,47)=0.8$, n.s.; Configuration $\times$ Revaluation, $F(8,47)=10.36, p<.001$; Stimulus Presentation $\times$ Revaluation, $F(8,47)=0.93$, n.s.; Configuration $x$ 
Stimulus Presentation $\times$ Revaluation, $F(8,47)=1.32$, n.s. (MANOVA source table is presented in Table 3 ).

Insert Tables $2 \& 3$ about here

$2 \times 2 \times 2$ ANOVAs (univariate analysis for each dependent measure) were generated (see Table 3 ) to examine the results for each independent variable and/or interaction of independent variables that yielded significant results in the MANOVA. Since the main effect of Stimulus Presentation and all the interactions it participated in were non-significant in the MANOVA, they were not assessed in separate ANOVAs below. These variables were Configuration (C), Revaluation (R), and Configuration $\times$ Revaluation $(C \times R)$. Results for Test 1 presses indicated, $C, F(1,54)=10.42$, $p<.01 ; R, F(1,54)=20.29, p<.001 ; C \times R, F(1,54)=0.01$, n.s.;. Test 1 $S_{2}$ consumption data yielded $C, F(1,54)=1.82$, n.S.; $R, F(1,54)=$ 28.36, $p<.001 ; C \times R, F(1,54)=6.67, p<.05$. Data for Test $2 S_{1}$ consumption found $C, F(1,54)=6.23, p<.05 ; R, F(1,54)=34.54$, $p<.001 ; C \times R, F(1,54)=20.99, p<.001$. For Test $2 \mathrm{H}_{2} \mathrm{O}$ consumption the pattern of results were as follows: $C, F(1,54)=12.67, p<.001$; $R, F(1,54)=6.61, p<.05 ; C \times R, F(1,54)=6.67, p<.05$. Test $3 S_{2}$ consumption results were: $C, F(1,54)=8.7, p<.01 ; R, F(1,54)=$ 3.58, n.s.; $\mathrm{C} \times \mathrm{R}, \mathrm{F}(1,54)=1.11$, n.s.. For Test $3 \mathrm{H}_{2} \mathrm{O}$ consumption the following was found: $C, F(1,54)=26.86, p<.001 ; R, F(1,54)=2.94$, n.s.; $C \times R, F(1,54)=6.43, p<.05$. Results for Test $4 S_{1}$ consumption indicated, $C, F(1,54)=48.91, p<.001 ; R, F(1,54)=$ 43.19, $p<.001 ; C \times R, F(1,54)=26.36, p<.001$; and lastly Test $4 S_{2}$ 
consumption results were: $C, F(1,54)=52.16, p<.001 ; R, F(1,54)=$ $4.0, p<.05 ; \quad C \times R, F(1,54)=6.63, p<.05$.

Comparisons were then conducted on the basis of apriori predictions made on theoretical grounds, in order to examine the specific pattern of results for particular behavioral effects. To investigate the conditioned taste aversion effect ( $L$ vs $N$ ), a transformation of $\mathrm{T}_{2} \mathrm{~S}_{1}$ and $\mathrm{T}_{2} \mathrm{H}_{2} \mathrm{O}$ data was performed such that the suppression ratio of the amount of $S_{1}$ consumed to total amount of fluid consumed [ $\left.\mathrm{S}_{1} /\left(\mathrm{S}_{1}+\mathrm{H}_{2} \mathrm{O}\right)\right]$ could be examined. A $2 \times 2$ ANOVA using Configuration $\times$ Revaluation yielded significant differences for both Configuration and Revaluation as well as an interaction (see Table 4): $C, F(1,59)=7.43, p<.01 ; R, F(1,59)=49.11, p<.001 ; C \times$ $R, F(1,59)=10.16, p<.01$, (Table 4 provides the mean suppression ratios for these groups and Table 5 the source table for this analysis). Tukey follow-ups indicated significant differences (i.e., $p<.05$ ) between group $B N$ (where quinine was $S_{1}$ and the animal experienced no illness) and all other groups, as well as group AN (where saccharin was $S_{1}$ and the animal experienced no illness) and all other groups. That is, $\mathrm{N}(\mathrm{NaCl}$, nonpoisoned) subjects consumed significantly more $S_{1}$ relative to total fluid intake than did $\mathrm{L}(\mathrm{LiCl}$, poisoned) subjects and, BN subjects consumed significantly more $S_{1}$ (quinine) relative to total fluid intake than did AN subjects (for whom $S_{1}$ was saccharin). See Figure 2 for this data. In addition, analyses on the absolute amounts of $\mathrm{S} 1$ and $\mathrm{H} 2 \mathrm{O}$ consumed on Test Day 2 indicated, for $C, F(1,59)=7.0, p<.05$, for $R, F(1,59)=0.15$, n.s., and for $C \times R, F(1,59)=18.55, p<.001$. Tukey follow up analyses $(p<.05)$ showed that animals in the $A N$ group consumed significantly 
more water than all other groups as well as more water than saccharin or quinine than any other group. There were no differences in the amount of water consumed by any of the remaining groups, that is, groups $A L, B L$, and $B N$ did not differ in the amount of water each consumed. Also to be noted, was the finding that there was no difference in water consumption for groups BL and BN. Nor was there a difference in the amount of water and quinine consumed by group BN. However, group BL consumed significantly less quinine than water. Additionally, group BL consumed significantly less quinine than group $B N$.

Since therewas a strong, theoretical reason to examine the effect of Sensory Preconditioning (or the lack of such an effect, as indicated by the MANOVA) for subjects receiving Paired vs Random stimuli presentations, a $2 \times 2 \times 2$ ANOVA $(C \times S t P \times R)$ for $T_{1} P$ was conducted (Source Table is presented in Table 6). Lever pressing contingently reinforced by $S_{2}$ should be indicative of the predictive and motivational value of $S_{2}$. The following results were found for $T_{1} P: C, F(1,56)=10.98, p<.001 ; S t P, F(1,56)=2.73$, n.s.; $R$, $F(1,56)=21.03, p<.001 ; C \times S, F(1,56)=3.98$, n.s.; $C \times R, F(1,56)=0.03$, n.S.;SxR, $F(1,56)=5.7, p<.05 ; \operatorname{CxS} \times R, F(1,56)=1.96$, n.s. Tukey followups indicated that group BRN (where saccharin was $S_{2}, S_{2}$ and $S_{1}$ were presented randomly, and no illness was experienced) pressed significantly more than all other groups and that there were no significant differences among any other groups (see Figure 3). Thus the interaction of random vs predictive presentation of $S_{2}$ and $S_{1}$ with illness vs no illness was entirely the result of the extremely 
high frequency of lever pressing in the BRN group as compared to all other groups.

In addition, a $2 \times 2 \times 2$ ANOVA ( $C \times S t P \times R$ ) was conducted to examine the $P$ vs $R$ Sensory Preconditioning effect of $T_{3} S_{2}$ and $\mathrm{T}_{3} \mathrm{H}_{2} \mathrm{O}$. A standard ratio transformation to examine suppression was calculated $\left[\mathrm{S}_{2} /\left(\mathrm{S}_{2}+\mathrm{H}_{2} \mathrm{O}\right)\right]$ to investigate the effect due to Stimulus Presentation ( $P$ vs $R$ ). $S_{2}$ consumption relative to total fluid intake should reflect differences due to the contingency between $\mathrm{S}_{1}$ and $\mathrm{S}_{2}$ (see Table 7 for means and sds). Results were as follows: $C, F(1,56)=29.86, p<.001$; StP, $F(1,56)=0.04$, n.s.; R, $F(1,56)=6.92, p<.05 ; C x S, F(1,56)=1.06$, n.s.; $C x R, F(1,56)=6.46$, p<.05; SxR, $F(1,56)=0.35$, n.s.; $\operatorname{CxS} x R, F(1,56)=0.13$, n.s., (see Table 8 for ANOVA source table). These data show no differences due to Stimulus Presentation ( $P$ vs $R$ ), suggesting the need to further examine these results to assess whether the absence of significant differences was due to all animals learning or none learning the relationship between $S 2$ and $S 1$. This is investigated in detail with post hoc analyses (see below). In order to examine the pattern of significant results, Tukey follow-up analyses were conducted and indicated that group APN consumed significantly $(p<.05)$ more $S_{2}$ relative to total fluid intake than groups $A R L, B R L, B P N, B R N$, and BPL. In addition, group ARN consumed significantly $(p<.05)$ more $S_{2}$ relative to total fluid intake than groups BRL, BPN, BRN, and BPL. No other differences were significant. Perhaps more interesting was the ANOVA of the absolute amounts of $\mathrm{S}_{2}$ and $\mathrm{H}_{2} \mathrm{O}$ yielding: $\mathrm{C}$, $F(1,56)=10.48, p<.01, R, F(1,56)=0.02$, n.s., and $C \times R, F(1,56)=2.57$, n.s. (see Table 9). Follow-up analyses were most revealing in the 
pattern of nonsignificant results. No differences were found for any A group, that is no differences were found for comparisons of water and quinine where quinine was $S_{2}$, regardless of the Stimulus Presentation (i.e., $P$ or $R$ ), nor illness or not to $S_{1}$ (saccharin). This pattern of results leads to a number of post hoc analyses which are presented later in this section.

Insert Tables 4, 5, 6,7,8 \& 9 about here

Another apriori analysis conducted, was an analysis of an emergence of a taste preference for saccharin and quinine during Sensory Preconditioning. A $2 \times 2$ mixed ANOVA was performed using $S_{1}$ and $S_{2}$ consumption on Day 5 (Stimulus) of Sensory Preconditioning between groups $\mathrm{A}$ and $\mathrm{B}$ (Configuration). Results yielded, $C, F(1,61)=4.43, p<.05 ; S, F(1,61)=1.34$, n.s., CxS, $F(1,61)=74.19, p<.001$ (Table 10 presents Source Table). Tukey follow-up tests indicated groups $\mathrm{AS}_{2}$ and $\mathrm{BS}_{1}$ consumed significantly more $(p<.05)$ than groups $A S_{1}$ and $B S_{2}$. That is, across Configuration, subjects consumed significantly more quinine (groups $A S_{2}$ and $B S_{1}$ ) than saccharin (groups $A S_{1}$ and $B S_{2}$ ). All subjects clearly preferred quinine.

Insert Table 10 about here

In light of the absence of significant differences between the Paired and Random groups, post hoc analyses were conducted. These analyses were employed in order to ascertain whether all 
groups learned a predictive relationship between $S_{1}$ and $S_{2}$ or if none of the groups established a predictive relationship between $S_{1}$ and $\mathrm{S}_{2}$.

Two $2 \times 2 \times 5$ (Configuration $\times$ Stimulus Presentation $\times$ Successive Days of Preconditioning) mixed ANOVAs were used to evaluate differences in specific taste (saccharin or quinine) consumption levels across Sensory Preconditioning days (see Tables 11 and 12 for ANOVA Source Tables). Differences among groups within any one taste would be due to the altered predictive value of that taste as $S_{2}$, as compared with the initial value of that specific taste as $S_{1}$ interacting with accumulated habituation to that taste. Groups and measures indicating saccharin consumption were $\mathrm{BPS}_{2}, \mathrm{BRS}_{2}, \mathrm{APS} \mathrm{S}_{1}$, and $\mathrm{ARS} \mathrm{S}_{1}$. The analysis indicated significant results for $C, F(1,55)=5.96, p<.05$, StP, $F(1,55)=6.56$, $p<.05, C x S, F(1,55)=6.38, p<.05$, and Day, $F(4,52)=32.16, p<.001 . A$ graphic presentation of the means is presented in Figure 2 . Groups and measures indicating quinine consumption were $\mathrm{APS}_{2}, \mathrm{ARS}_{2}$, $B P S_{1}$, and $B R S_{1}$ (because quinine was $S_{2}$ in the $A$ groups and quinine was $S_{1}$ in the $B$ groups). Significant results were found for Day, $F(4,52)=123.76, p<.001$, and Day $\times C, F(4,52)=4.82, p<.01$. Figure 3 presents the means for quinine consumption across days.

Differences due to the differing predictive value should emerge across Sensory Preconditioning days for a particular taste stimulus (either saccharin or quinine) as the predictive value of the Paired S2 stimulus is altered while the value of the same taste stimulus remains unaltered in the Random groups. As Figures 5 and 6 demonstrate, no such pattern developed. 
Insert Tables $11 \& 12$ and

Figures $5 \& 6$ about here

\section{Discussion}

The results of this experiment provide ample support for the prediction regarding the primary effect of the devaluation of the US. Subjects exposed to $\mathrm{LiCl}$ during Revaluation consumed significantly less $S_{1}$ than groups that were not exposed to $S_{1}$ devaluation (i.e., $\mathrm{NaCl}$ groups) for both the saccharin and quinine USs. Such findings indicate the development of a conditioned taste aversion in L groups, as compared to $\mathrm{N}$ groups, as a result of the revaluation of the motivational value of $S_{1}$. This finding is crucial because it indicates that animals in the $L$ groups modified their behavior based on the altered motivational value of $S_{1}$. In addition, this result important in analyzing the pattern of results for the Paired versus Random manipulation.

Data also indicated differences due to Configuration ( $A$ vs $B$ ) on all dependent measures, indicating a clear initial preference for quinine over saccharin that emerged during the Sensory Preconditioning (training) phase, and was maintained through differences in the $S_{1}$ consumption ratio on Test Day 2. Test Day 2 showed differences between $\mathrm{BN}$ and $\mathrm{AN}$ groups. The only difference between these groups was that $S_{1}$ was quinine for the $B$ groups and saccharin for the A groups. Neither group was made ill therefore, the original value of $S_{1}$ (the US) was not altered. This finding indicates that $B$ subjects consumed significantly more quinine 
relative to their total fluid intake (quinine and water) than $A$ subjects consumed of saccharin relative to their total fluid intake (i.e., saccharin and water), and supports the conclusion regarding a greater motivational value for the quinine solution.

Additionally, analyses from Test Day 2 using the absolute amounts of water, saccharin and quinine, as appropriate for each respective group, show that animals in $\mathrm{AL}, \mathrm{AN}$, and $\mathrm{BL}$ groups discriminated their respective $S_{1}$ fluid from water, while group BN did not. This finding is important because it demonstrates that saccharin is clearly discriminable from water but that quinine only appears to be discriminable from water when subjects have been made ill to it. Group BL clearly shows a difference in the amount of quinine and water consumed, whereas group BN does not. This finding indicates that quinine and water are equally preferred, and either 1) that animals can not distinguish quinine from water unless they have been made ill to quinine, or 2) that the animals are able to discriminate but do not demonstrate any behavioral changes unless they are made ill to quinine. This information also is germane to the assessment of the data regarding the Stimulus Presentation (Paired vs. Random) variable and will be examined in that context.

A very surprising result was revealed by the comparisons of groups designed to receive contingently Paired presentations of $S_{2}$ and $S_{1}$, to groups receiving noncontingent, truly Random presentations. This basic manipulation of contingency of stimuli was the procedure employed to establish the predictive relationship between the stimuli in the $P$ groups, versus the $R$ 
control groups, for whom no predictive relationship between $S_{1}$ and $\mathrm{S}_{2}$ was in place. Establishment of the predictive relationship in $\mathrm{P}$ groups should give $S_{2}$ "predictive" value for $P$ the groups only and therefore comparisons between $P$ and $R$ groups would provide information regarding this predictive value. Comparisons of differing motivational values among the different $P$ groups (e.g., $A P L$ vs. APN, and BPL vs. BPN) would provide empirical findings resulting from changes in motivational values in $S_{2}$. None of the measures reflecting the predictive (Paired) versus the nonpredictive (Random) relationship between $S_{1}$ and $S_{2}$ were significant. MANOVA and subsequent ANOVAs regarding Stimulus Presentation (i.e., Paired vs Random) found no significant results for all dependent measures (see Source Tables $2 \& 3$ ). In addition, post hoc comparisons for Stimulus Presentation (i.e., Paired vs Random) regarding the relative amount of $S_{2}$ to total fluid intake ( $\mathrm{S}_{2} /\left(\mathrm{S}_{2}+\mathrm{H}_{2} \mathrm{O}\right)$ on Test Day 3 ) and $\mathrm{S}_{2}$ as an outcome (as indicated by the number of responses emitted in the free operant behavior class - $\left.T_{1} P\right)$, also revealed nonsignificant effects.

This unexpected finding of nonsignificant effects could be understood as either (1) that both groups (Paired and Random) learned some degree of predictive relationship between $S_{1}$ and $S_{2}$, or (2) that none of the groups learned a predictive relationship between $S_{1}$ and $S_{2}$ and only sensitization, and/or habituation to the stimuli occurred.

In order to further investigate these possibilities an examination of the amount of $\mathrm{S}_{1}$ and $\mathrm{S}_{2}$ consumed over Sensory Preconditioning days was conducted. Such an investigation should 
reflect the establishment (or absence) of the predictive relationship between $S_{2}$ and $S_{1}$ because as preconditioning progresses, if $S_{2}$ comes to predict $S_{1}$, there should be a change in the value of $S_{2}$ in the direction of the value of $S_{1}$. This would be indicated by comparing fluid consumption for a particular taste when it is $S_{2}$ to the consumption for that same taste on the same day when it is $S_{1}$. If $S_{2}$ becomes more like the $S_{1}$ it predicts, and if saccharin is $S_{2}$ and quinine is $S_{1}$ (as in the $B$ groups), then saccharin should become more valuable than saccharin as $S_{1}$ (as in the A groups), and therefore consumed in greater quantity. This should occur because saccharin as $S_{2}$ predicts quinine, a preferred taste and if $S_{2}$ predicts $S_{1}$, it should have an enhanced value compared to its original value as reflected by saccharin consumption when it is $S_{1}$. The reverse should occur if quinine was $S_{2}$ and predicted saccharin, since saccharin was less preferred, quinine would become less preferred than if it was not predictive of saccharin. If both the Paired and Random groups had learned the predictive relationship between $S_{2}$ and $S_{1}$ the preceding pattern of results would be found in both $P$ and $R$ conditions. Thus, in both $P$ and $R$ conditions, responses to $S_{2}$ should become more similar to those to $S_{1}$ across Sensory Preconditioning days as $S_{2}$ acquired the predictive value of $S_{1}$ (for saccharin consumption over Sensory Preconditioning days group $B P>B R=A P=A R$ and for quinine consumption over Sensory Preconditioning days group $A P<A R=B P$ $=\mathrm{BR}$ ).

Another possible explanation is that no groups learned a contingency between $S_{2}$ and $S_{1}$ and that sensitization could have 
occurred during training. Subjects in the Random groups response to $S_{2}$ could be enhanced due to repeated exposures to it. This would mean that an enhancement of neophobic behavior to the novel tastes (saccharin and quinine) would occur across Preconditioning days. The behavioral manifestations of such an effect would be response suppression across the Sensory Preconditioning phase. $S_{2}$ fluid consumption would start at very low levels on day 1 and remain at low levels through day 5 for both $S_{1}$ and $S_{2}$. The animals would respond as if the tastes were novel and exhibit continued neophobic behavior (e.g., avoidance of the taste through suppression of drinking the specific fluid).

A final possibility is that no predictive relationship was established between $S_{1}$ and $S_{2}$ in any of the groups and that habituation rather than sensitization occurred. Here, subjects would become less responsive to the novelty of the stimuli due to repeated presentations, and a decreased level of neophobia to the novel tastes would occur. Behavioral indicators of a habituation effect would be gradual increased consumption of the novel tastes across Sensory Preconditioning days.

Post hoc analyses indicated that none of the groups established a predictive relationship between $S_{1}$ and $S_{2}$. The empirical findings presented in Figures 5 and 6 demonstrate a pattern of results which clearly supports habituation as an explanation. Animals consumed more of each fluid. There is no inhibition of quinine consumption demonstrated for group AP, nor is there a conditioning enhancement of saccharin consumption for 
group BP as would be indicated if animals learned a predictive relationship between $S_{1}$ and $S_{2}$.

The unexpected absence of a preconditioning effect in the Paired groups prompted a more integrated examination of the patterns of results from both apriori and post hoc comparisons. Why would no preconditioning occur under circumstances where learning was optimized? The animals were in a motivated state (hungry and thirsty), valuable outcomes were available for drinking, and animals did consume the solutions. Clearly the tastes, saccharin and quinine, were distinct. Data indicate that consumption of each was suppressed when it was the taste that animals were made ill to (Test Day $2 S_{1}$ consumption data). However, data from Test Day $2\left(\mathrm{~S}_{1}\right.$ vs $\left.\mathrm{H}_{2} \mathrm{O}\right)$ also showed that there were no differences between the amounts of quinine and water consumed when animals were not made ill to quinine. Moreover, on Test Day 3 , when quinine was $S_{2}$, there were no differences among any of the $A$ groups regarding quinine and water consumption. On both Test Days 2 and 3 all animals show no evidence of a discrimination between quinine and water except for animals that were specifically made ill to the taste of quinine (i.e., the $B L$ group).

These results, taken collectively, suggest that illness to quinine is what produced the quinine-water discrimination, but that in the absence of experiencing the salient contingency of illness to quinine, water and quinine were not differentially responded to. Such a finding has strong implications for the Sensory Preconditioning phase results of this study. Since all 
animals had access to water in their home cages daily during all phases (except Revaluation and Testing), and were exposed to water in the training apparatus during Acclimation, animals in both the Paired and Random groups experienced presentations of saccharin and water in a random fashion. And, since water and quinine were not discriminated by subjects prior to being made ill to quinine, no contingency between saccharin and quinine could be established in either direction. In essence, there was no contingent relationship in place for the Paired subjects. That is, no reliable and predictive, informative, relationship between $S_{1}$ and $S_{2}$ was ever established. Results indicate that all subjects responded as if no learning occurred during Sensory Preconditioning. Therefore, if no predictive relationship was established, only habituation to the taste of saccharin took place. Also, as a result of the absence of this predictive relationship, none of the differential experimental conditions were in place and subjects were unable to predict the coming of either the original or altered value of the US.

Why did animals that were not made ill to the taste of quinine not demonstrate discriminatory responding to quinine and water? The data demonstrate that the animals can discriminate between the two tastes but that they did not do so until they had been made ill to the taste of quinine. One possible explanation for such responding is latent discrimination learning. The animals experienced the stimuli in their environment, but did not respond differentially until the circumstances required them to. Previous research (Gibson,E.J. \& Walk,1956; Gibson, E.J., Walk, Pick, \& Tighe, 1958; Walk, Gibson, E.J., Pick, \& Tighe, 1958) indicates that 
discrimination learning can occur in the absence of an overt behavioral responses and can influence subsequent behavior.

Reiss and Wagner (1972) suggest that animals ignore stimuli which have no significance, that is, those which have no particular value or use to the animal at the time they are experienced. They also found that this ignoring of nonsignificant stimuli was related to latent inhibition and subsequent response suppression. Although latent inhibition was not revealed in the animals made ill to quinine, the research of Gibson and her colleagues, and that of Reiss and Wagner (1972), together suggest that perhaps the animals in the present experiment did not alter their performance because the stimuli involved were not significant until they were made ill. If stimuli are predictive of biologically or emotionally significant events, then a change in performance will be observed. Otherwise, no alteration in behavior is made.

Such a prospect is consistent with the notion of behavior as being biologically adaptive. It is more efficient for an animal to only respond and make adjustments in behavior to events which are of importance, while it still gathers some degree of information regarding the environment. Perhaps of more current relevance is that these findings are also consistent with a cognitive view of choice behavior. Signal detection theory support a cognitive perspective and proposes that animals respond to stimuli in their environment based on two major components, the sensory value of the particular stimulus ( $\left.d^{\prime}\right)$ and the costs and benefits of detecting the stimulus. This second component, the evaluative component, implies a choice regarding the value of the outcomes available. A 
cognitive perspective suggests that decisions are made based on judgements regarding conditional probabilities of outcomes available (see Rachlin, 1989, 1991, for a detailed discussion of these topics).

The findings of the current research although not designed to deal with such issues, are consistent with the above cited research regarding latent discrimination and learning. Signal detection theory and latent discrimination learning, ultimately, lend support to a cognitive-behavioral synthesis.

Some of the answers to Rozeboom's (1958) empirical construction on the question of "what is learned" still need to be explored. To date, information regarding the extent to which a CS retains or alters its original incentive value as a function of the initial motivational value of the US it predicts, and the extent to which that value is affected by the altered value of the stimulus it predicts (the US), is still incomplete. What remains is the need to investigate the motivational value of a predictive cue in an altered setting as an outcome to a free operant, under a variety of motivational conditions with a variety of predictive relationships employing empirically, discriminable stimuli.

This may be accomplished through the use of the basic design employed in this study with the following adjustments:

1) Use stimuli of more biological/emotional significance with an overt behavioral response. This will allow for an examination of the establishment of the predictive versus random relationship during acquisition through an examination of the learning curve during conditioning. 2) Maintain use of a Test phase which examines the 
incentive value of the $\mathrm{CS}$ as an outcome for a new response and comparing it with non-contingent presentations of the CS. This is a crucial test of stimulus value due to its direct nature. However, maximize the possibility of the test situation and create a more sensitive measure by employing a leaner reinforcement schedule and a longer session length. A leaner reinforcement schedule would allow for a longer time interval and more behavior to occur without the delivery of the outcome (and consummatory behaviors) distupting the response rate. In addition a longer session length would allow for more observations to be made and a more stable response rate to emerge. 


\section{References}

Bond, N.W. \& DiGuisto, E.L. (1976). One trial higher-order conditioning of a taste aversion. Australian Journal of Psychology, 28, 53-55.

Braveman, N.S., \& Jarvis, P.S. (1978). Independence of neophobia and taste aversion learning. Animal Learning and Behavior, 6, 406-412.

Brogden, W.J. (1939). Sensory pre-conditioning. Journal of Experimental Psychology, 25, 323-332.

Cohen, S.L., Calisto, G., \& Lentz, B.E. (1979) Separating the reinforcing and discriminative properties of brief-stimulus presentations in second-order schedules. Journal of the Experimental Analysis of Behavior, 32, 149-156.

Colwill, R.M. \& Rescorla, R. A. (1985a). Instrumental responding remains sensitive to reinforcer devaluation after extensive training. Journal of Experimental Psychology: Animal Behavior Processes, 11, 520 - 536.

Colwill, R.M. \& Rescorla, R. A. (1985b). Extensive training, partial reinforcement, and temporal gaps do not affect $S$-S learning in second-order autoshaping. Animal Learning \& Behavior, 13 , 165-170.

Colwill, R.M. \& Rescorla, R. A. (1986). Associative structures in instrumental learning. In G.H. Bower (Ed.), The psychology of learning and motivation (Vol. 20, pp. 55-104). New York: Academic Press.

Domjan, M. \& Burkhard, B. ,(1982). The principles of learning and behavior. Monterey, CA:Brooks/Cole Publishing Co.

Egger, M.D., \& Miller, N.E. (1962). Secondary reinforcement in rats as a function of information value and reliability of the stimulus. Journal of Experimental Psychology, 64, 97-104. 
Egger, M.D., \& Miller, N.E. (1963). When is a reward reinforcing? An experimental study of the information hypothesis. Journal of Comparative and Physiological Psychology, 56, 132-137.

Garcia, J., Kimeldorf, D.J., \& Koelling, R.A. (1955). Conditioned aversion to saccharin resulting from exposure to gamma radiation. Science, 122, 157-158.

Garcia, J., \& Koelling, R.A. (1966). Relation of cue to consequence in avoidance learning. Psychonomic Science, 4, 123-124.

Harlow, H.F. (1949). The formation of learning sets. Psychological Review, $\underline{56}, 51-65$.

Kalat, J.W. (1974). Taste salience depends on novelty, not concentration, in taste aversion learning in the rat. Journal of Comparative and Physiological Psychology, 86, 47-50.

Kamin, L.J. (1968). "Attention-like" processes in classical conditioning. In M.R. Jones (Ed.), Miami Symposium on the prediction of behavior: Aversive stimulation. Miami: University of Miami Press.

Kamin, L.J. (1969). Predictability, surprise, attention, and conditioning. In B.A. Campbell \& R.M. Church (Eds.) Punishment and aversive behavior. New York: Appleton-Century-Crofts.

Kohler, W. (1925). The Mentality of Apes. New York: Harcourt, Brace, and World.

Pavlov, I. (1927). Conditioned Reflexes. Oxford: Oxford University Press.

Rachlin, H. (1989). Judgement decision, and choice: A cognitive/behavioral synthesis. New York: W.H. Freeman and Company.

Rachlin, H. (1991). Introductuion to modern behaviorism, 3rd ed.. New York: W.H. Freeman and Company.

Rescorla, R.A. (1980). Pavlovian second order conditioning: Studies in associative learning. Hillsdale, NJ: Erbaum. 
Rescorla, R.A. (1987). A pavlovian analysis of goal directed behavior. American Psychologist, 42, 119-129.

Rescorla, R.A. (1988). Pavlovian conditioning: It's not what you think it is. American Psychologist, 43, 151-160.

Rescorla, R.A. \& Cunningham, C.L. (1978). Journal of Experimental Psychology: Animal Behavior Processes, 4, 267-275.

Rescorla, R.A., \& Wagner, A.R. (1972). A theory of Pavlovian conditioning: Variations in the effectiveness of reinforcement and nonreinforcement. In A.H. Black \& W.F. Prokasy (Eds.), Classical conditioning II: Current research and theory. New York: Appleton-Century-Crofts.

Revusky, S.H., \& Garcia, J. (1970). Learned associations over long delays. In G.H.Bower \& J.T. Spence (Eds.), The psychology of learning and motivation (Vol. 4). New York: Academic Press.

Rozeboom, W.W. (1958). "What is learned?" - An empirical enigma. Psychological Review, 65, 22-33.

Seligman, M.E.P. (1970). On the generality of the laws of learning. Psychological Review, 77, 406-418.

Tolman, E.C., (1932). Purposive behavior in animals and men. New York: Appleton-Century.

Tolman, E.C., (1948). Cognitive maps in rats and men.

Psychological Review, 55, 189-208.

Tolman, E.C., (1959). Principles of purposive behavior. In S. Koch (Ed.), Psychology: A Study of a Science (Vol. 2). New York:McGraw-Hill.

Wagner, A.R., \& Rescorla, R.A. (1972). Inhibition in Pavlovian conditioning: Application of a theory. In R.A. Boakes \& M.S. Halliday (Eds.), Inhibition and learning. London: Academic Press. 
Table 1

Schematic Representation of the Overall Experimental Design

\begin{tabular}{|c|c|c|c|c|c|c|c|c|}
\hline ACCLIMATION & \multicolumn{8}{|c|}{ (THE SAME FOR ALL SUBJECTS) } \\
\hline $\begin{array}{l}\text { BAR PRESS } \\
\text { TRAINING } \\
\end{array}$ & \multicolumn{8}{|c|}{ (THE SAME FOR ALL SUBJECTS) } \\
\hline \multirow[t]{2}{*}{$\begin{array}{l}\text { SENSORY } \\
\text { PRECONDITIONING }\end{array}$} & \multicolumn{8}{|c|}{\begin{tabular}{l|l} 
CONFIGURATION & \\
A & B \\
S$_{2}=$ QUININE & $S_{2}=S A$ \\
$S_{1}=$ SACCHARIN & $S_{1}=Q L$ \\
\end{tabular}} \\
\hline & \multicolumn{2}{|c|}{$\begin{array}{l}\text { PAIRED } \\
\mathrm{S}_{2}-\mathrm{S}_{1}\end{array}$} & \multicolumn{2}{|c|}{$\begin{array}{l}\text { RANDOM } \\
\mathrm{S}_{2} / \mathrm{S}_{1}\end{array}$} & \multicolumn{2}{|c|}{$\begin{array}{l}\text { PAIRED } \\
\mathrm{S}_{2}-\mathrm{S}_{1}\end{array}$} & \multicolumn{2}{|c|}{$\begin{array}{l}\text { RANDOM } \\
\mathrm{S}_{2} / \mathrm{S}_{1}\end{array}$} \\
\hline REVALUATION & $\mathrm{Li}$ - & $\begin{array}{l}\mathrm{Na}- \\
\mathrm{Cl}\end{array}$ & $\mathrm{Li}-$ & $\begin{array}{l}\mathrm{Na}- \\
\mathrm{C}\end{array}$ & $\begin{array}{l}\mathrm{Li}- \\
\mathrm{Cl}\end{array}$ & $\begin{array}{l}\mathrm{Na}- \\
\mathrm{Cl}\end{array}$ & $\begin{array}{l}\mathrm{Li}- \\
\mathrm{Cl}\end{array}$ & $\begin{array}{l}\mathrm{Na}- \\
\mathrm{Cl}\end{array}$ \\
\hline TEST 1 & \multicolumn{8}{|c|}{$\begin{array}{l}\text { SAME FOR ALL SUBJECTS* } \\
\text { CONTINGENT BAR PRESSING FOR } \mathrm{S}_{2}\end{array}$} \\
\hline TEST 2 & \multicolumn{8}{|c|}{$\begin{array}{l}\text { SAME FOR ALL SUBJECTS* } \\
\text { TWO BOTTLE CHOICE: } \mathrm{S}_{1} \& \mathrm{H}_{2} \mathrm{O} \\
\end{array}$} \\
\hline TEST 3 & \multicolumn{8}{|c|}{$\begin{array}{l}\text { SAME FOR ALL SUBJECTS* } \\
\text { TWO BOTTLE CHOICE: } \mathrm{S}_{2} \& \mathrm{H}_{2} \mathrm{O}\end{array}$} \\
\hline TEST 4 & \multicolumn{8}{|c|}{$\begin{array}{l}\text { SAME FOR ALL SUBJECTS* } \\
\text { TWO BOTTLE CHOICE: } S_{1} \& S_{2}\end{array}$} \\
\hline
\end{tabular}

* $\mathrm{S}_{1}$ and $\mathrm{S}_{2}$ as indicated by the appropriate configuration 
Table 2

Means and Sds for Each Group across all Measures

Measur

$\mathrm{e}$

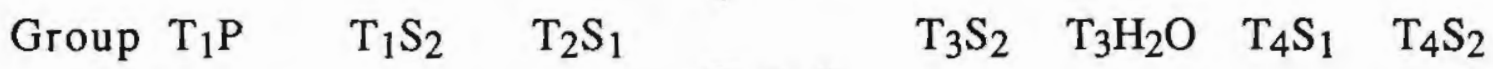

$\mathrm{T}_{2} \mathrm{H}_{2} \mathrm{O}$

\begin{tabular}{lrrrrrrrr}
\hline APL & & & & & & & & \\
X & 41.62 & 2.93 & 1.87 & 13.62 & 4.37 & 8.50 & 1.62 & 9.68 \\
Sd & 21.66 & 1.80 & 1.72 & 4.71 & 3.46 & 5.92 & 0.74 & 3.33 \\
APN & & & & & & & & \\
X & 109.12 & 5.31 & 2.50 & 9.50 & 7.00 & 5.25 & 3.12 & 13.68 \\
Sd & 55.43 & 2.57 & 0.96 & 4.72 & 2.71 & 2.71 & 1.64 & 3.08 \\
ARL & & & & & & & & \\
X & 20.42 & 1.42 & 1.57 & 15.42 & 4.71 & 9.28 & 1.57 & 10.92 \\
Sd & 16.21 & 1.13 & 0.73 & 6.24 & 2.48 & 5.31 & 0.44 & 5.55 \\
ARN & & & & & & & & \\
X & 120.62 & 6.68 & 2.12 & 7.68 & 5.37 & 4.87 & 2.37 & 14.62 \\
Sd & 80.08 & 2.28 & 0.74 & 3.44 & 2.64 & 1.72 & 0.87 & 4.90 \\
BPL & & & & & & & & \\
X & 93.37 & 2.81 & 0.93 & 7.06 & 2.93 & 11.81 & 3.25 & 4.62 \\
Sd & 57.61 & 1.09 & 0.77 & 3.27 & 1.14 & 3.16 & 2.42 & 1.84 \\
BPN & & & & & & & & \\
X & 111.57 & 4.14 & 5.35 & 6.57 & 3.57 & 11.00 & 10.85 & 5.71 \\
Sd & 73.42 & 2.01 & 2.44 & 3.82 & 1.30 & 4.00 & 5.78 & 3.14 \\
BRL & & & & & & & & \\
X & 90.87 & 3.00 & 0.93 & 8.00 & 4.00 & 10.75 & 2.81 & 7.68 \\
Sd & 58.69 & 1.77 & 0.90 & 4.27 & 1.53 & 1.66 & 1.98 & 3.21 \\
BRN & & & & & & & & \\
X & 237.37 & 4.25 & 5.37 & 8.18 & 4.18 & 13.25 & 11.62 & 5.18 \\
Sd & 136.94 & 1.83 & 3.10 & 4.01 & 1.85 & 2.71 & 3.76 & 1.57 \\
\hline
\end{tabular}


Table 3

MANOVA Source Summary Table

\begin{tabular}{lrcc} 
Source & $\mathrm{T}^{2}$ & $\mathrm{df}$ & $\mathrm{F}$ \\
\hline Configuration & 206.30 & 8 & $22.45 *$ \\
Stimulus & 5.59 & 8 & .06 \\
$\begin{array}{l}\text { Presentation } \\
\text { Revaluation }\end{array}$ & 179.56 & 8 & $19.54^{*}$ \\
C x StP & 7.35 & 8 & 0.80 \\
Cx R & 95.25 & 8 & $10.36^{*}$ \\
StP x R & 8.53 & 8 & 0.93 \\
C x StP x R & 12.16 & 8 & 1.32 \\
\hline$* \mathrm{p}<.001$ & & &
\end{tabular}


Table 4

Mean Suppression Ratios for Test Day $2[\mathrm{~S} 1 /(\mathrm{S} 1+\mathrm{H} 2 \mathrm{O})]$

\begin{tabular}{lll}
\hline Group & Mean & Sd \\
\hline AL & .11 & .07 \\
AN & .23 & .10 \\
BL & .10 & .08 \\
BN & .43 & .21 \\
\hline
\end{tabular}


Table 5

$2 \times 2$ ANOVA Source Table for Test $2-S_{1}$ Consumption Ratio

\begin{tabular}{llllr}
\hline Source & SS & df & MS & F \\
\hline Configuration & 0.1246 & 1 & 0.1246 & $7.43^{*}$ \\
Revaluation & 0.8238 & 1 & 0.8238 & $49.11^{*}$ \\
Cx R & 0.1704 & 1 & 0.1704 & $10.16^{*}$ \\
Error & & & & \\
Ratio & 0.9897 & 59 & 0.0167 & \\
\hline *p<.01 & & &
\end{tabular}


Table 6

$2 \times 2 \times 2$ ANOVA Source Table for Test 1 - Frequency of Lever Pressing

\begin{tabular}{lcccc} 
Source & SS & df & MS & F \\
\hline Configuration & 56109.76 & 1 & 56109.76 & $10.98 *$
\end{tabular}

Stimulus

Presentation

$13953.51 \quad 1$

13953.51

2.73

Revaluation

107502.01

$\mathrm{C} \times \mathrm{StP}$

20341.89

107502.01

$21.03 *$

$\mathrm{C} \times \mathrm{R}$

StP $\times$ R

159.39

20341.89

$3.98 *$

$\mathrm{C} \times \mathrm{StP} \times \mathrm{R}$

29112.89

159.39

0.03

Error

$10025.01 \quad 1$

29112.89

$5.70 *$

${ }^{*} p<.05$

286250.1256

$10025.01 \quad 1.96$

5111.60 
Table 7

Mean Suppression Ratios for Test Day 3 [S2/(S2+H2O)]

\begin{tabular}{lll}
\hline Group & Mean & Sd \\
\hline APL & .36 & .24 \\
APN & .56 & .19 \\
ARL & .32 & .13 \\
ARN & .51 & .17 \\
BPL & .20 & .06 \\
BPN & .24 & .11 \\
BRL & .26 & .09 \\
BRN & .23 & .08 \\
\hline
\end{tabular}


Table 8

$2 \times 2 \times 2$ ANOVA Source Table for Test $3-S_{2}$ Consumption Ratio

\begin{tabular}{lllll}
\hline Source & SS & df & MS & F \\
\hline Configuration & 0.6643 & 1 & 0.6643 & $29.86 *$ \\
Stimulus & & & & \\
Presentation & 0.0010 & 1 & 0.0010 & 0.04 \\
Revaluation & 0.1539 & 1 & 0.1539 & $6.92 *$ \\
Cx StP & 0.0235 & 1 & 0.0235 & 1.06 \\
Cx R & 0.1437 & 1 & 0.1437 & $6.46 *$ \\
StP x R & 0.0077 & 1 & 0.0077 & 0.35 \\
Cx StP x R & 0.0029 & 1 & 0.0029 & 0.13 \\
Error & 1.2459 & 56 & 0.0222 & \\
& & & & \\
\hline *p<.05 & & & &
\end{tabular}


Table 9

$2 \times 2 \times 2 \times 2$ ANOVA Source Table for Test 3 -Absolute Amounts of $\underline{\mathrm{S}}_{2}$ and $\mathrm{H}_{2} \mathrm{O}$ Consumed

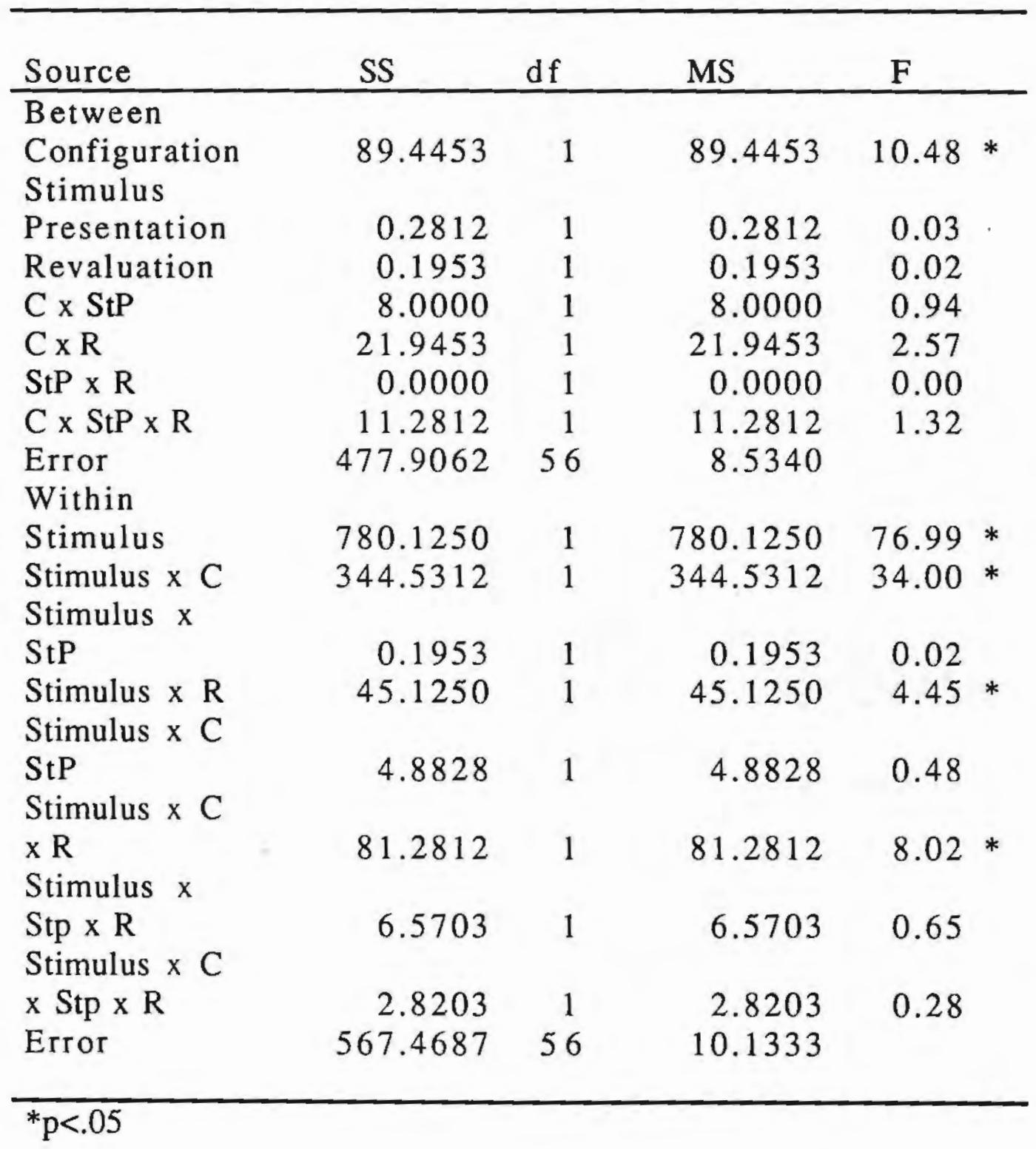


Table 10

$2 \times 2$ ANOVA Source Table for Saccharin/Quinine Preference on Day 5 of Sensory Preconditioning

\begin{tabular}{|c|c|c|c|c|c|}
\hline Source & SS & $\mathrm{df}$ & MS & $\mathbf{F}$ & \\
\hline \multicolumn{6}{|l|}{ Between } \\
\hline Configuration & 21.4395 & 1 & 21.4395 & 4.43 & * \\
\hline Erior & 295.5287 & 61 & 4.8447 & & \\
\hline \multicolumn{6}{|l|}{ Within } \\
\hline Stimulus & 8.1269 & 1 & 8.1269 & 1.34 & \\
\hline Stimulus $\mathrm{x} C$ & 451.5902 & 1 & 451.5902 & 74.19 & $*$ \\
\hline Error & 371.2827 & 61 & 6.0866 & & \\
\hline
\end{tabular}


Table 11

$2 \times 2 \times 5$ ANOVA Source Summary Table - Saccharin Consumption per Day during Sensory Preconditioning

\begin{tabular}{lllll}
\hline Source & SS & df & MS & F \\
\hline Between & & & & \\
Configuration & 32.9890 & 1 & 32.9890 & $5.96 *$ \\
Stimulus & & & & \\
Presentation & 36.3484 & 1 & 36.3484 & $6.56 *$ \\
Cx StP & 35.3611 & 1 & 35.3611 & $6.38 *$ \\
Error & 304.6252 & 55 & 5.5386 & \\
Within & & & & \\
Day & 345.2238 & 4 & 86.3059 & $37.99 *$ \\
D xC & 12.1609 & 4 & 3.0402 & 1.34 \\
D x StP & 10.5147 & 4 & 4.6286 & 2.04 \\
D x C X StP & 2.6581 & 4 & 0.6645 & 0.29 \\
Error & 499.7799 & 220 & 2.2717 & \\
& & & & \\
*p<.05 & & &
\end{tabular}


Table 12

$2 \times 2 \times 5$ ANOVA Source Summary Table - Quinine Consumption per Day during Sensory Preconditioning

\begin{tabular}{lrrrr}
\hline Source & \multicolumn{1}{c}{ SS } & df & MS & F \\
\hline Between & & & & \\
Configuration & 13.7491 & 1 & 13.7491 & 1.04 \\
Stimulus & & & & \\
Presentation & 0.8158 & 1 & 0.8158 & 0.06 \\
Cx StP & 0.4610 & 1 & 0.4610 & 0.03 \\
Error & 729.4715 & 55 & 13.2631 & \\
Within & & & & \\
Day & 1340.0796 & 4 & 335.0199 & $77.09 *$ \\
DxC & 125.2539 & 4 & 31.3132 & $7.21 *$ \\
Dx StP & 30.6407 & 4 & 7.6601 & 1.76 \\
Dx C x StP & 12.3889 & 4 & 3.0972 & 0.71 \\
Error & 956.1107 & 220 & 4.3459 & \\
& & & & \\
\hline
\end{tabular}

${ }^{*} \mathrm{p}<.01$ 
65

Figure 1

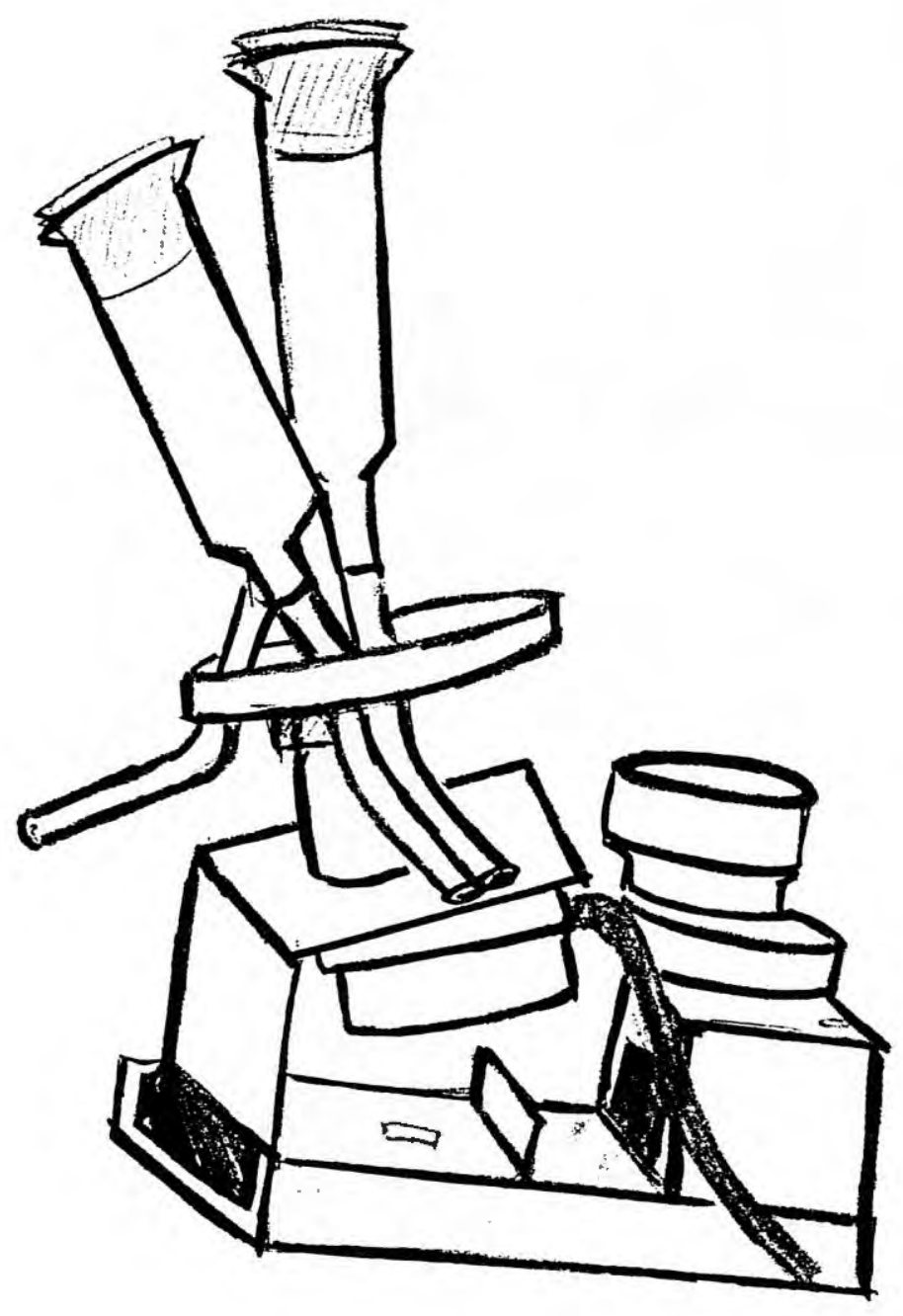


Figure 2

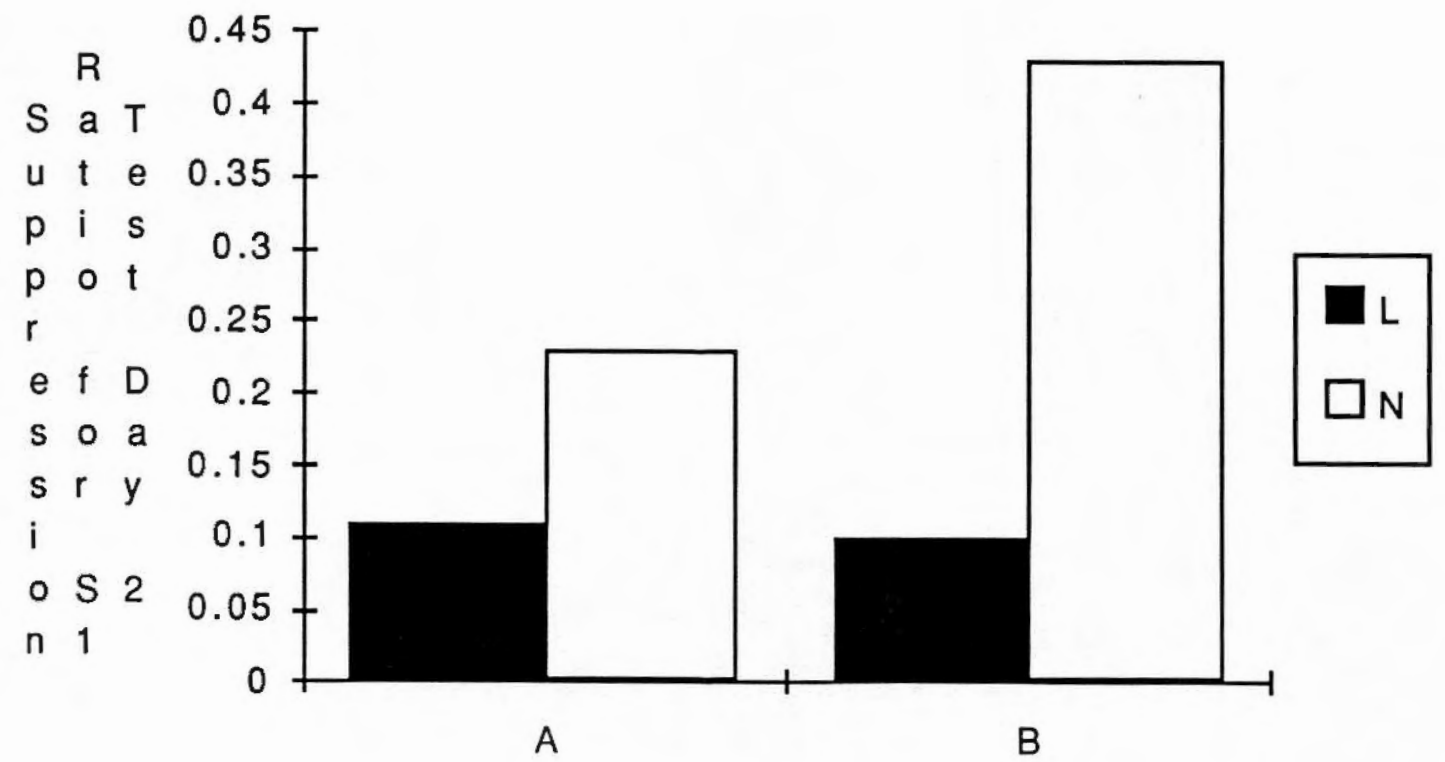


Figure 3

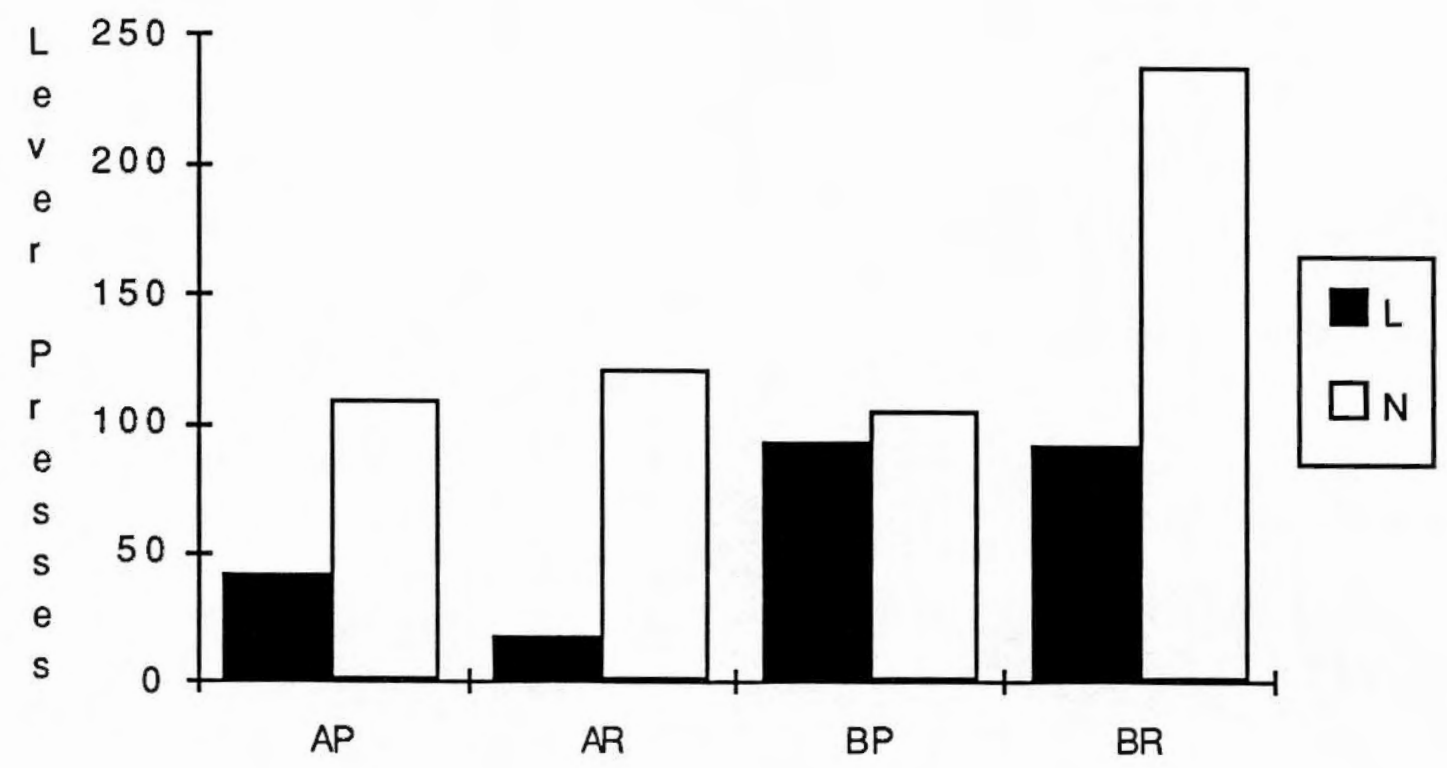


Figure 4

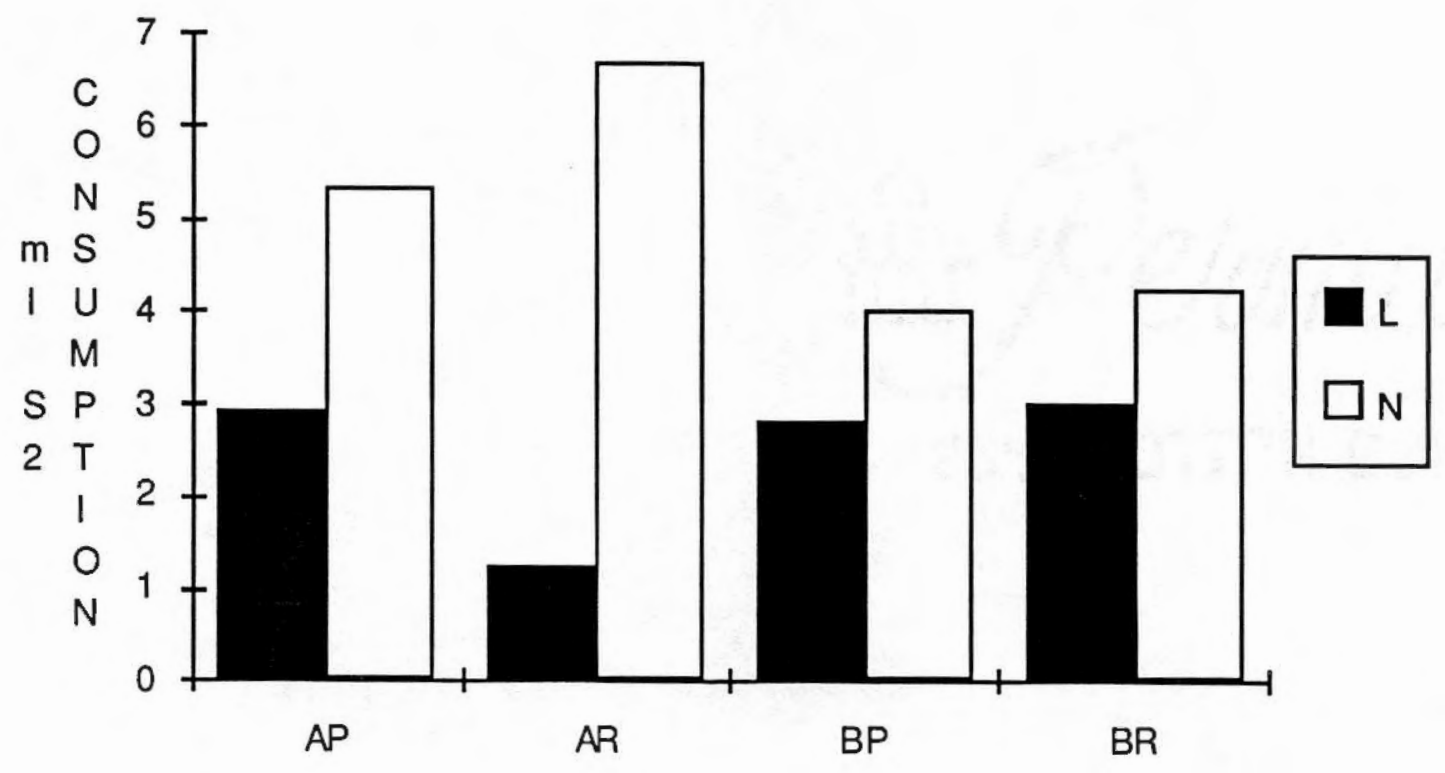


Figure 5

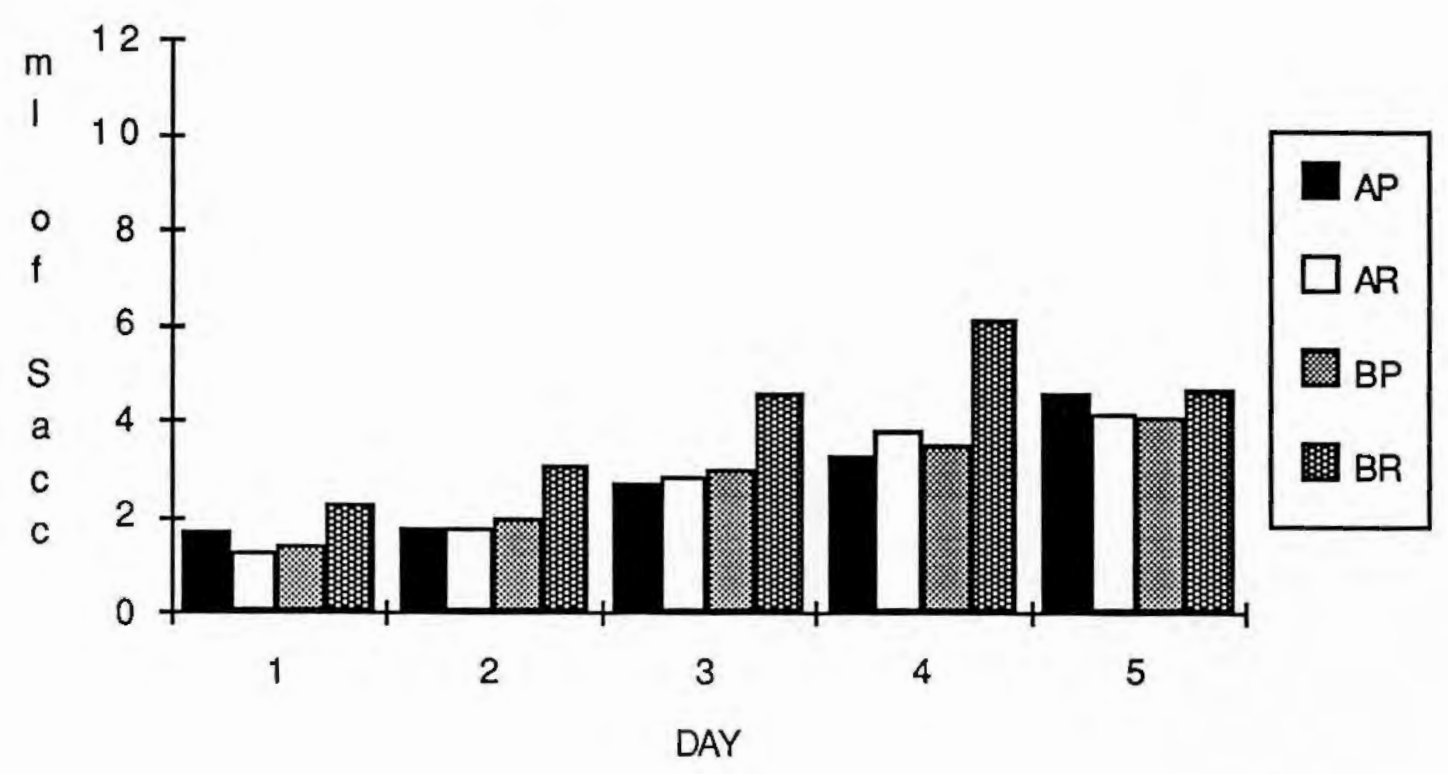


Figure 6

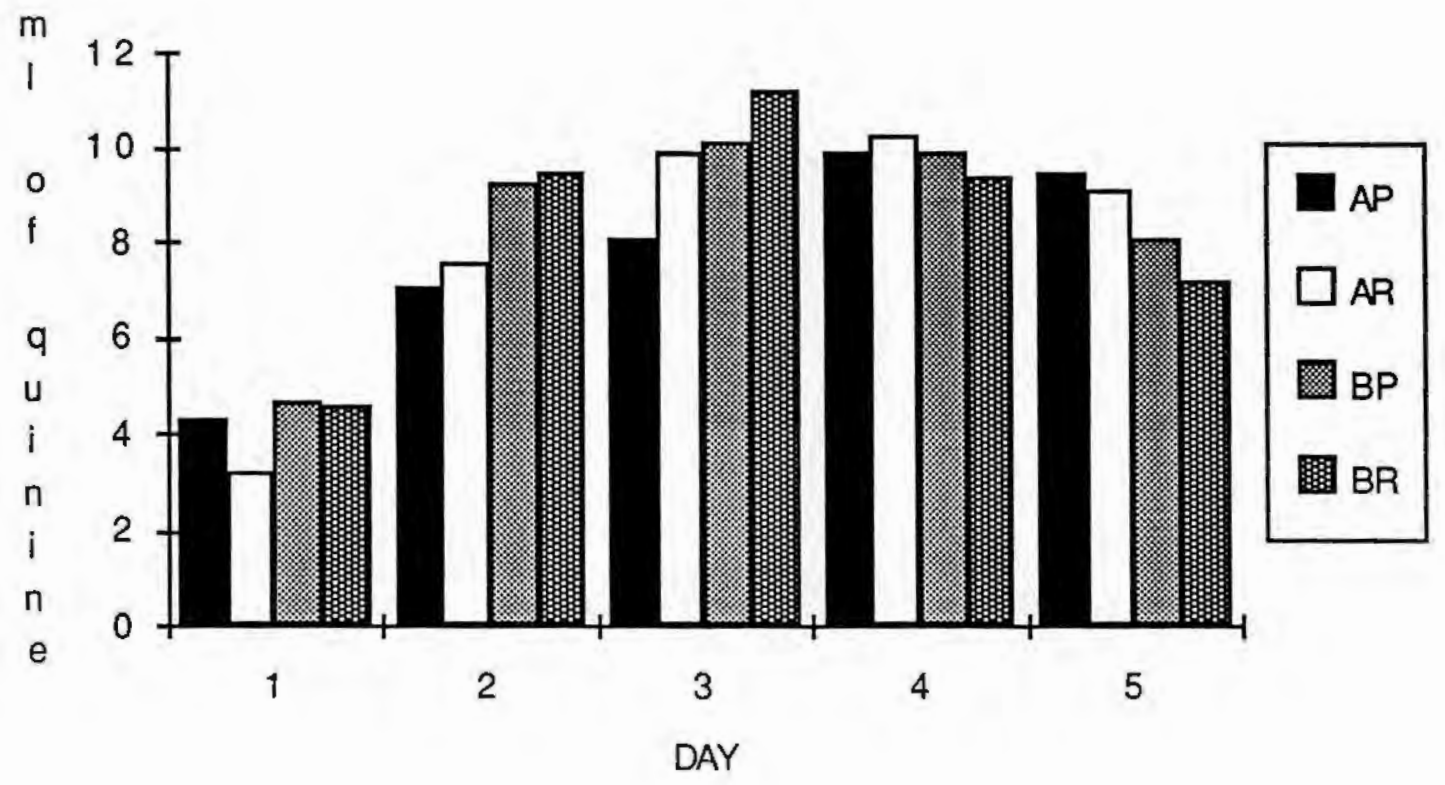




\section{Bibliography}

Bond, N.W. \& DiGuisto, E.L. (1976). One trial higher-order conditioning of a taste aversion. Australian Journal of Psychology, 28, 53-55.

Braveman, N.S., \& Jarvis, P.S. (1978). Independence of neophobia and taste aversion learning. Animal Learning and Behavior, 6, 406-412.

Brogden, W.J. (1939). Sensory pre-conditioning. Journal of Experimental Psychology, 25, 323-332.

Cohen, S.L., Calisto, G., \& Lentz, B.E. (1979) Separating the reinforcing and discriminative properties of brief-stimulus presentations in second-order schedules. Journal of the Experimental Analysis of Behavior, 32, 149-156.

Colwill, R.M. \& Rescorla, R. A. (1985a). Instrumental responding remains sensitive to reinforcer devaluation after extensive training. Journal of Experimental Psychology: Animal Behavior Processes, 11, 520 - 536.

Colwill, R.M. \& Rescorla, R. A. (1985b). Extensive training, partial reinforcement, and temporal gaps do not affect $S-S$ learning in second-order autoshaping. Animal Learning \& Behavior, 13, $165-170$.

Colwill, R.M. \& Rescorla, R. A. (1986). Associative structures in instrumental learning. In G.H. Bower (Ed.), The psychology of learning and motivation (Vol. 20, pp. 55-104). New York: Academic Press.

Domjan, M. \& Burkhard, B. ,(1982). The principles of learning and behavior. Monterey, CA:Brooks/Cole Publishing Co.

Egger, M.D., \& Miller, N.E. (1962). Secondary reinforcement in rats as a function of information value and reliability of the stimulus. Journal of Experimemntal Psychology, 64, 97-104.

Egger, M.D., \& Miller, N.E. (1963). When is a reward reinforcing? An experimental study of the information hypothesis. Journal of Comparative and Physiological Psychology, 56, 132-137. 
Garcia, J., Kimeldorf, D.J., \& Koelling, R.A. (1955). Conditioned aversion to saccharin resulting from exposure to gamma radiation. Science, $122,157-158$.

Garcia, J., \& Koelling, R.A. (1966). Relation of cue to consequence in avoidance learning. Psychonomic Science, 4, 123- 124.

Johnson-Laird, P.N., \& Wason, P.C. (Eds.). (1980). Thinking: Readings in cognitive science. Cambridge: Cambridge University Press.

Harlow, H.F. (1949). The formation of learning sets. Psychological Review, 56, 51-65.

Kalat, J.W. (1974). Taste salience depends on novelty, not concentration, in taste aversion learning in the rat. Journal of Comparative and Physiological Psychology, 86, 47-50.

Kamin, L.J. (1968). "Attention-like" processes in classical conditioning. In M.R. Jones (Ed.), Miami Symposium on the prediction of behavior: Aversive stimulation. Miami: University of Miami Press.

Kamin, L.J. (1969). Predictability, surprise, attention, and conditioning. In B.A. Campbell \& R.M. Church (Eds.) Punishment and aversive behavior. New York: AppletonCentury-Crofts.

Kohler, W. (1925). The Mentality of Apes. New York: Harcourt, Brace, and World.

Logan, F.A., \& Ferraro, D.P. (1978). Systematic analyses of learning and motivation. New York: John Wiley \& Sons.

Pavlov, I. (1927). Conditioned Reflexes. Oxford: Oxford University Press.

Pfaffmann, C. The pleasures of sensation. Psychological Review, 1960 67, 253-268. 
Rachlin, H. (1989). Judgement decision, and choice: A

cognitive/behavioral synthesis. New York: W.H. Freeman and Company.

Rachlin, H. (1991). Introductuion to modern behaviorism, 3rd ed.. New York: W.H. Freeman and Company.

Rescorla, R.A. (1980). Pavlovian second order conditioning: Studies in associative learning. Hillsdale, NJ: Erbaum.

Rescorla, R.A. (1987). A pavlovian analysis of goal directed behavior. American Psychologist, 42, 119-129.

Rescorla, R.A. (1988). Pavlovian conditioning: It's not what you think it is. American Psychologist, 43, 151-160.

Rescorla, R.A. \& Cunningham, C.L. (1978). Journal of Experimental Psychology: Animal Behavior Processes, 4, 267-275.

Rescorla, R.A., \& Wagner, A.R. (1972). A theory of Pavlovian conditioning: Variations in the effectiveness of reinforcement and nonreinforcement. In A.H. Black \& W.F. Prokasy (Eds.), Classical conditioning II: Current research and theory. New York: Appleton-Century-Crofts.

Revusky, S.H., \& Garcia, J. (1970). Learned associations over long delays. In G.H.Bower \& J.T. Spence (Eds.), The psychology of learning and motivation (Vol. 4). New York: Academic Press.

Rozeboom, W.W. (1958). "What is learned?" - An empirical enigma. Psychological Review, 65, 22-33.

Seligman, M.E.P. (1970). On the generality of the laws of learning. Psychological Review, 77, 406-418.

Swartz, B. (1984). Psychology of learning \& behavior (2nd ed.). New York: W.W. Norton and Company, Inc.

Tabachnick, B.G. \& Fidell, L.S. (1989). Using Multivariate Statistics, 2nd ed. New York:Harper Collins.

Tolman, E.C., (1932). Purposive behavior in animals and men. New York: Appleton-Century. 
Tolman, E.C., (1948). Cognitive maps in rats and men. Psychological Review, 55, 189-208.

Tolman, E.C., (1959). Principles of purposive behavior. In S. Koch (Ed.), Psychology: A Study of a Science (Vol. 2). New York:McGraw-Hill.

Wagner, A.R., \& Rescorla, R.A. (1972). Inhibition in Pavlovian conditioning: Application of a theory. In R.A. Boakes \& M.S. Halliday (Eds.), Inhibition and learning. London: Academic Press.

Winer, B.J., (1971). Statistical Principles in Experimental Desion, 2nd ed., New York: McGraw-Hill. 